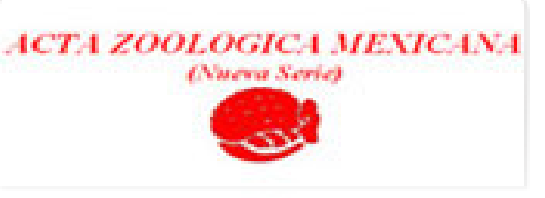

\section{Acta Zoológica Mexicana (nueva serie)}

ISSN: 0065-1737

azm@ecologia.edu.mx

Instituto de Ecología, A.C.

México

Muñoz Hernández, Adrián; Morón, Miguel Angel; Aragón, Agustín

Coleoptera scarabaeoidea de la región de Teziutlán, Puebla, México

Acta Zoológica Mexicana (nueva serie), vol. 24, núm. 3, 2008, pp. 55-78

Instituto de Ecología, A.C.

Xalapa, México

Disponible en: http://www.redalyc.org/articulo.oa?id=57524305

Cómo citar el artículo

- Número completo

- Más información del artículo

Página de la revista en redalyc.org

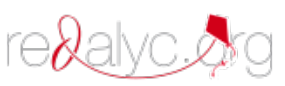

Sistema de Información Científica

Red de Revistas Científicas de América Latina, el Caribe, España y Portugal Proyecto académico sin fines de lucro, desarrollado bajo la iniciativa de acceso abierto 


\title{
COLEOPTERA SCARABAEOIDEA DE LA REGIÓN DE TEZIUTLÁN, PUEBLA, MÉXICO
}

\author{
Adrián Muñoz-HernándeZ1, Miguel Angel Morón² y Agustín Aragón1 \\ 1 Departamento de Agroecología y Ambiente, Instituto de Ciencias, Benemérita Universidad \\ Autónoma de Puebla, 14 Sur 6301, San Manuel, Puebla, Puebla 72570 MÉXICO \\ aragon@siu.buap.mx \\ 2 Departamento de Biología de Suelos, Instituto de Ecología, A.C. Apartado Postal 63, \\ Xalapa, Veracruz 91000, MÉXICO miguel.moron@inecol.edu.mx
}

\begin{abstract}
RESUMEN
Con el propósito de evaluar la riqueza, abundancia y fenología de las especies de Coleoptera Scarabaeoidea o Lamellicornia de la región de Teziutlán, Puebla, se realizaron colectas mensuales entre mayo de 1999 y junio de 2000, en sitios con bosques de pino-encino-liquidámbar o zonas de cultivo situados entre 1,990 y $2,000 \mathrm{~m}$ de altitud. Se capturaron 2,082 ejemplares que representan a 59 especies de 29 géneros, 18 tribus y 7 subfamilias de Melolonthidae, Scarabaeidae y Passalidae, entre las que destacan Phyllophaga godmani (Bates), Isonychus piperitus Bates, Anomala terroni Morón, Chrysina peruviana Kirby, Plusiotis aurofoveata Morón, Cyclocephala fasciolata Bates, Dynastes hyllus Chevrolat, Deltochilum mexicanum Bates, Ontherus mexicanus Harold, Onthophagus cyanellus Bates, Passalus punctatostriatus Percheron, Proculejus hirtus (Truqui) y Odontotaenius zodiacus Truqui. La riqueza específica es elevada y representativa de ese tipo de bosques a pesar de la perturbación existente. Las especies más abundantes fueron Phyllophaga vetula (Horn), P. xanthe (Bates), Macrodactylus mexicanus Burmeister, Hoplia squamifera Burmeister, Cyclocephala jalapensis Casey, C. weidneri Endrodi, y Chrysina macropus Francillon. Los adultos de la mayor parte de las especies están activos entre abril y junio. De acuerdo con el índice de Simpson la fauna de lamelicornios de Teziutlán presenta un $80 \%$ de similitud con la fauna de las montañas del noreste de Hidalgo, un 33\% con la región vecina de Cuetzalan, Puebla, y un $17 \%$ con el área de Los Tuxtlas, Veracruz. Se incluye una clave para separar las 59 especies encontradas.
\end{abstract}

Palabras Clave: Melolonthidae, Scarabaeidae, Passalidae, taxonomía, distribución, bosque de pinoencino con liquidámbar.

\section{ABSTRACT}

A study of the species richness, abundance and phenology of the Scarabaeoidea beetle fauna of the mountains of Puebla, México is presented. Monthly data were obtained during May 1999 to June 2000 in pine-oak-sweet gum forests and crop lands, located at 1,990-2,000 m of altitude. Records of 59 species, 29 genera, 18 tribes and 7 subfamilies of Melolonthidae, Scarabaeidae and Passalidae, represented by 2,082 specimens, are included. Phyllophaga godmani (Bates), Isonychus piperitus Bates, Anomala terroni Morón, Chrysina peruviana Kirby, Plusiotis aurofoveata Morón, Cyclocephala fasciolata Bates, Dynastes hyllus Chevrolat, Deltochilum mexicanum Bates, Ontherus mexicanus Harold, Onthophagus cyanellus Bates, Passalus punctatostriatus Percheron, Proculejus hirtus (Truqui) and Odontotaenius zodiacus Truqui, were the most interesant species collected. High and representative species richness was found instead of the disturbs in the forests. Phyllophaga vetula (Horn), P. xanthe 
(Bates), Macrodactylus mexicanus Burmeister, Hoplia squamifera Burmeister, Cyclocephala jalapensis Casey, C. weidneri Endrodi, and Chrysina macropus Francillon, were the most abundant species in the samples. Adults of many species are active during April to June. Scarab beetle fauna of Teziutlán area is $80 \%$ similar (Simpson) with the species found in the mountains at northeast of Hidalgo, Mexico; $33 \%$ similar with the species from the neighboring area of Cuetzalan, Puebla, and 17\% similar with Los Tuxtlas, Veracruz. A key to the 59 species is included.

Key Words: Melolonthidae, Scarabaeidae, Passalidae, taxonomy, distribution, pine-oak with sweet gum forest.

\section{INTRODUCCIÓN}

Los estudios faunísticos regionales sobre coleópteros Lamellicornios o Scarabaeoidea de México fueron iniciados por Miguel A. Morón en 1974, con el propósito a largo plazo de lograr un inventario preciso y actualizado de estas especies en la República Mexicana (Morón et al. 1997). En el transcurso de los siguientes 30 años se reunió información sobre los escarabajos que habitan en bosques de coníferas y encinos del Estado de México y Durango (Morón 1981, Morón \& Zaragoza 1976, Morón \& Deloya 1990), en bosques tropicales perennifolios de Veracruz y Chiapas (Morón 1979, Morón et al. 1985), en bosques tropicales caducifolios de Jalisco, Morelos y Yucatán (Morón et al. 1988, Deloya \& Morón 1994, Reyes-Novelo \& Morón 2005), en bosques mesófilos de montaña de Hidalgo y Chiapas (Morón 1984, Morón-Ríos \& Morón 2001), y en ambientes de transición entre distintos tipos de bosques y zonas cultivadas en Nayarit, Puebla y Chiapas (Morón et al. 1998, 2000, Aragón et al. 2001, Carrillo-Ruiz \& Morón 2003, Alcázar-Ruiz et al. 2003).

El presente trabajo tuvo como objetivos el determinar la riqueza específica, la abundancia y la fenología de los coleópteros Lamelicornios o Scarabaeoidea en la región de Teziutlán, estado de Puebla, y comparar su fauna con las de otras localidades del país.

\section{MATERIALES Y MÉTODOS}

Área de estudio. Teziutlán se encuentra ubicado al norte del Estado de Puebla (Fig. 1), en la parte norte del eje neovolcánico, casi colindando con el estado de Veracruz, en las coordenadas $97^{\circ} 21.6^{\prime}$ lat. $\mathrm{N}$ y $19^{\circ} 48.9^{\prime}$ long W con una altitud entre 1,990 y 2,000 m.snm. (INEGI 1993a). Dentro de esta zona encontramos la cuenca llamada " La Gran Caldera de Teziutlán “. Los tipos de suelo que predominan en esta zona son los andosoles y regosoles, los cuales presentan un color grisáceo oscuro en la capa superficial y pardo o pardo amarillento en las capas mas profundas, son ricos en materia orgánica y tienen un alto contenido de nutrientes (INEGI 1993b). Predominan dos tipos de clima, el templado-húmedo con lluvias todo el año C(fm), y el templado-húmedo con abundantes lluvias en verano $\mathrm{C}(\mathrm{m})$. La región está sujeta a cambios bruscos de temperatura y presión debido a las perturbaciones atmosféricas del Golfo de México, sin embargo la temperatura solo varía entre los $12^{\circ}$ y los $18^{\circ} \mathrm{C}$ (Fig. 2) (INEGI 1993a). 
Acta Zool. Mex. (n.s.) 24(3) (2008)

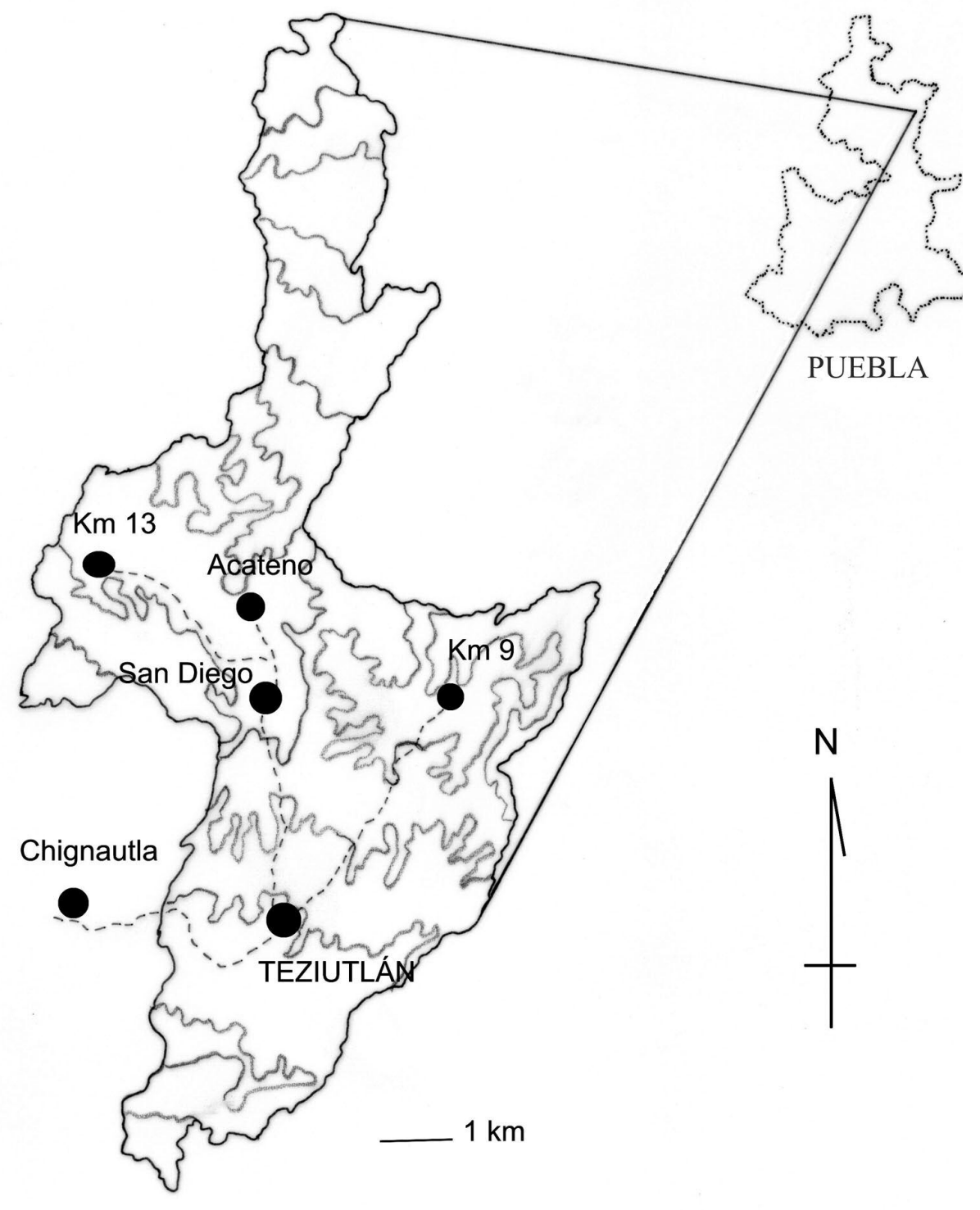

Figura 1. Localidades de colecta en el municipio de Teziutlán, Puebla, México. 


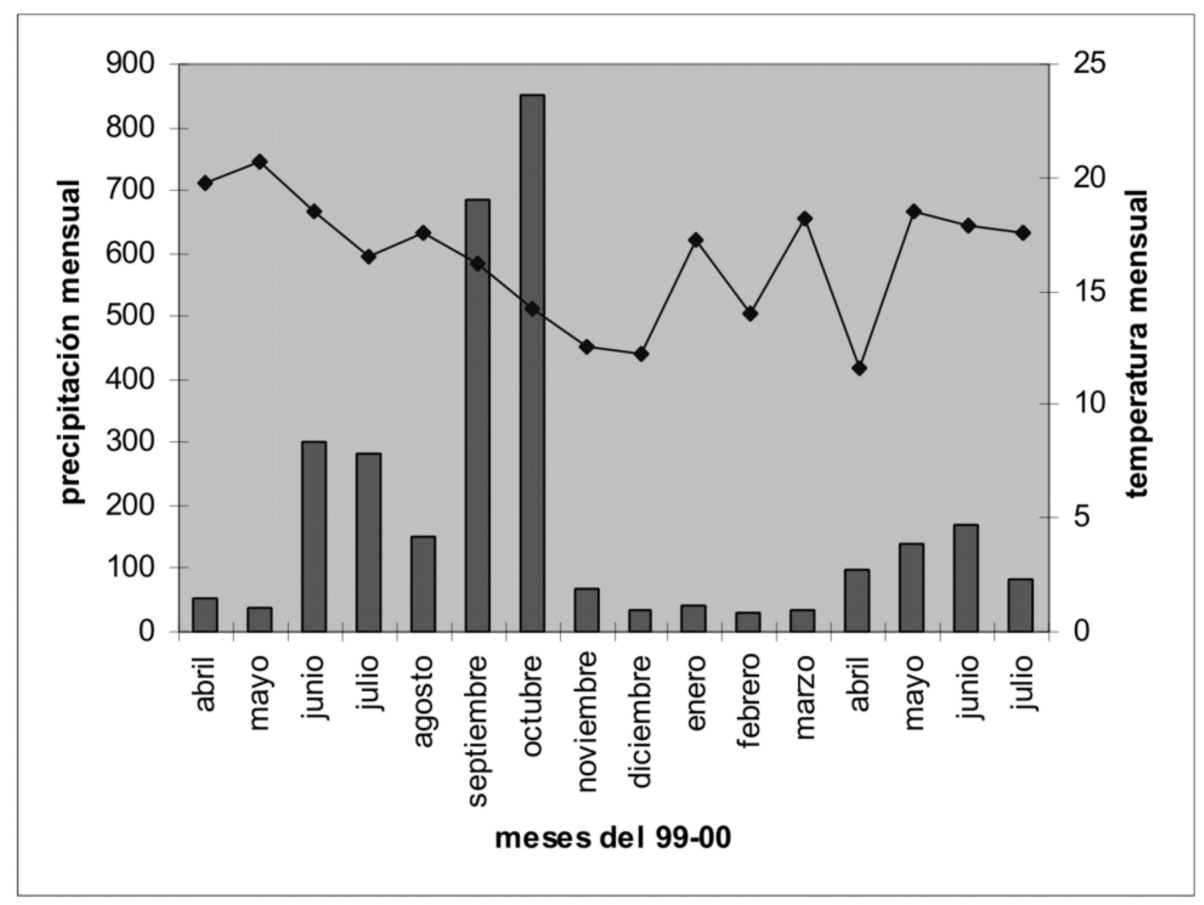

Figura 2. Temperatura y precipitación en el municipio de Teziutlán, Puebla.

Los afluentes de esta zona son los ríos Necaxa, Laxaxalpa y Apulco. El tipo de vegetación que se encuentra en la región es un mosaico de bosque de liquidámbar, bosque de pino-encino y bosque de encino-pino. Las especies de árboles que se encuentran son: Pinus ayacahuite Ehrenb., P. cembroides Zucc., P. leiophylla Schl. et Cham., P. michoacana cornuta Martínez, P. montezuma Lamb., P. patula Schl. et Cham., P. pseudostrobus Lindl., P. rudis Endl., P. strobus chiapensis Martínez, $P$. teocote Schl. et Cham., Quercus sororia Liebm., Q. furfuracea Liebm. y $Q$. polymorpha Schl. et Cham. Cabe mencionar que una buena parte de estas especies ya no son tan abundantes debido a la intensa explotación de estos bosques (INEGI, 1993b).

El tipo de agricultura que predomina es la de temporal, entre los cultivos podemos encontrar maíz, fríjol, legumbres y forrajes. También se cultivan árboles frutales propios del clima, como lo son el ciruelo, peral, manzano, tecojote y capulín. El laboreo que comúnmente se lleva a cabo es el de tipo manual (INEGI, 1993a).

Las colectas se realizaron entre mayo de 1999 y junio del 2000, durante tres días y tres noches cada mes, en un bosque de pino-encino poco perturbado ( $\mathrm{Km} 9$ 
carretera Teziutlán- Hueyapan; $19^{\circ} 51^{\prime} 51^{\prime \prime} \mathrm{N}, 97^{\circ} 19^{\prime} 45^{\prime}$ 'O; 1,515 m), en una zona de cultivo (San Juan Acateno; 19 52'04" N, 97²1'09”O; 1,600 m), y en un bosque de pino inducido (Km 13 carretera Teziutlán-Martínez de la Torre; 1953’42” N, $97^{\circ} 23^{\prime} 59^{\prime}$ 'O; 1,656 m). En estos tres sitios (Fig. 1) se utilizaron necrotrampas permanentes NTP-80 (Morón \& Terrón 1984), trampa de luz tipo pantalla con dos lámparas de vapor de mercurio de 120 watts, y se realizaron colectas directas en el suelo, bajo estiércol, dentro de troncos derribados, y en el follaje o las flores de arbustos o herbáceas (Morón 1997). En las cercanías de Chignautla (1950’09”N, 97²0'09'O; 1,700 m) se empleó la trampa de luz, y en San Diego (1951'02”N, $97^{\circ} 21^{\prime} 06^{\prime \prime}$ O; 1,800 m) y San Juan Acateno (Fig. 1) se realizaron colectas nocturnas bajo el alumbrado público. Estas actividades totalizaron 395 horas efectivas de colecta (140 horas nocturnas, 180 horas con NTP-80 y 75 horas diurnas en colecta directa). Los ejemplares obtenidos se procesaron con los métodos convencionales para conservarlos en alfiler y están depositados en las colecciones entomológicas del Departamento de Agroecología y Ambiente, BUAP (DAGAM) Puebla, y el Instituto de Ecología, A.C. (IEXA) Xalapa, Veracruz.

Los resultados de este trabajo se compararon con los datos obtenidos en estudios realizados anteriormente en localidades de Durango, Hidalgo, Jalisco, Morelos, Nayarit, Puebla, y Veracruz (Morón 1979, 1981, 1994, Morón et al. 1988, 1998, 2000, Deloya et al. 1995, Carrillo \& Morón 2003), empleando un método de agrupamiento por enlaces simples, apoyado en una matriz analizada con Winclada ver. 1.00 .08 (Nixon 2002) y NONA ver. 2.0 (Goloboff 1999) mediante una rutina de búsqueda heurística (100 réplicas) para exponer gráficamente las relaciones entre las localidades con referencia en una área ancestral hipotética codificada con ceros.

\section{RESULTADOS}

Se capturaron 2,082 ejemplares que representan a 59 especies de 29 géneros, 18 tribus y 7 subfamilias de Melolonthidae, Scarabaeidae y Passalidae (Apéndice I). A continuación se comenta la composición específica para cada género, y en el Apéndice II se presenta una clave para identificar estos taxa.

MELOLONTHIDAE, MELOLONTHINAE, Melolonthini

Phyllophaga Harris. Se capturaron 300 ejemplares representantes de ocho especies de los subgéneros Phytalus, Chlaenobia y Phyllophaga (s.str.). En San Diego se encontraron cuatro especies: $P$. atra, $P$. godmani, $P$. vetula y $P$. sp. aff. ciliatipes; en el km. 13 carretera TeziutlánHueyapan se localizaron $P$. angulicollis, $P$. godmani y $P$. scissa; en Chignautla se obtuvieron $P$. vetula y $P$. xanthe; en el km 9 carretera Teziutlán-Martínez de la Torre, sólo se registró $P$. vetula; y en San Juan Acateno únicamente se colectó una hembra de $P$. aff. bucephala. Las especies más abundantes fueron $P$. vetula y $P$. xanthe, representadas por 151 y 123 ejemplares respectivamente. Phyllophaga atra, $P$. godmani y $P$. sp. aff. ciliatipes se registraron solo en febrero y marzo, antes de las lluvias de primavera; mientras que $P$. angulicollis, P. bucephala, 
$P$. scissa y $P$. vetula volaron en mayo y junio, después de las lluvias de primavera; $y$ P. xanthe se capturó durante julio y agosto, con las lluvias veraniegas.

MELOLONTHINAE, Diplotaxini

Diplotaxis Kirby. Sólo se colectaron 10 ejemplares atraídos por las luces que representan a tres especies. Durante mayo en San Diego se encontraron D. fossifrons y D. simplex; en Chignautla se obtuvieron $D$. consentanea y $D$. simplex; y en el km. 9 carretera TeziutlánMartínez de la Torre se registró $D$. consentanea.

MELOLONTHINAE, Macrodactylini

Macrodactylus Latreille. Durante las colectas diurnas sobre herbáceas y arbustos realizadas en los alrededores de Chignautla entre junio y agosto de 1999 se capturaron 174 ejemplares de M. mexicanus y 8 ejemplares de M. nigripes.

Isonychus Mannerheim. Un total de 63 ejemplares fueron atraídos por las luces de la trampa o del alumbrado público entre abril y junio en el km.13 carretera Teziutlán- Hueyapan, en San Diego, en el km. 9 Teziutlan-Martinez de la Torre, y en San Juan Acateno; 49 de ellos corresponden a I. piperitus y 14 son I. ocellatus.

\section{HOPLIINAE}

Hoplia Illiger. En las localidades de San Juan Acateno, km. 13 Teziutlán-Hueyapan, San Diego, km. 9 Teziutlán-Martínez de la Torre y Chignautla, fueron atraídos por las luces 368 ejemplares (119 machos y 249 hembras) de H. squamifera durante febrero (64), marzo (80), abril (108), mayo (10) y junio (106). Una pareja de H. asperula se colectó dentro de una flor no identificada en el km. 9 Teziutlán-Martínez de la Torre, durante el mes de abril.

DYNASTINAE, Cyclocephalini

Cyclocephala Latreille. Se obtuvieron un total de 645 ejemplares atraídos por las luces, que representan a siete especies, con diferente composición en cada localidad. Cyclocephala lurida coahuilae y $C$. fasciolata solo se registraron en Chignautla, junto con C. sexpunctata y C.weidneri pero con distinta fenología (Cuadro 1). Cyclocephala lunulata solo se encontró en el km. 13 Teziutlán-Hueyapan, junto con C. jalapensis, C. melanocephala, C. sexpunctata y C. weidneri, pero también con diferente fenología (Cuadro 1). En el km. 9 Teziutlan-Martínez de la Torre, se capturaron C. jalapensis, C. melanocephala, C. sexpunctata y C. weidneri; en San Diego se colectaron C. jalapensis, C. melanocephala y C. weidneri; y en San Juan Acateno se obtuvieron $C$. jalapensis y $C$. weidneri. En resumen, las especies de este género mostraron dos períodos de vuelo, el primero durante las lluvias de primavera (mayo-junio) y el segundo en el período de máxima precipitación del año correspondiente al mes de octubre. Es interesante anotar que entre julio y septiembre no se capturó ningún ejemplar de Cyclocephala (Cuadro 1). Ancognatha Erichson. Se colectaron 26 ejemplares de A. falsa (Fig. 3) atraídos por las luces de la trampa o el alumbrado público en Chignautla, el km. 13 Teziutlán-Hueyapan, San Diego, y el km. 9 Teziutlán-Martínez de la Torre, durante febrero (2), mayo (20), junio (4) y julio (2).

\section{DYNASTINAE, Pentodontini}

Ligyrus Burmeister. Durante el mes octubre en San Juan Acateno y San Diego se encontraron 5 hembras de $L$. sallei atraídas por el alumbrado público.

Orizabus Fairmaire. En Chignautla y San Diego se colectaron 10 ejemplares de O. clunalis atraídos por las luces de la trampa o el alumbrado público, durante febrero (2), mayo (6) y julio (2). 
Cuadro 1. Fenología de las especies de Cyclocephala en la región de Teziutlán (1999-2000) (ejemplares).

\begin{tabular}{l|ccc|ccc}
\hline \multicolumn{1}{c|}{ Especies } & Marzo & Abril & Mayo & Junio & Julio-Sep. & Octubre \\
\hline C. fasciolata & --- & --- & --- & --- & --- & 4 \\
C. jalapensis & 1 & 6 & 66 & 40 & --- & --- \\
C. lunulata & --- & --- & 2 & 1 & --- & 76 \\
C. lurida & --- & --- & --- & --- & --- & 42 \\
C. melanocephala & --- & --- & 2 & --- & --- & 2 \\
\hline C. sexpunctata & --- & --- & 10 & 2 & --- & --- \\
\hline C. weidneri & --- & --- & 391 & --- & --- & --- \\
\hline
\end{tabular}

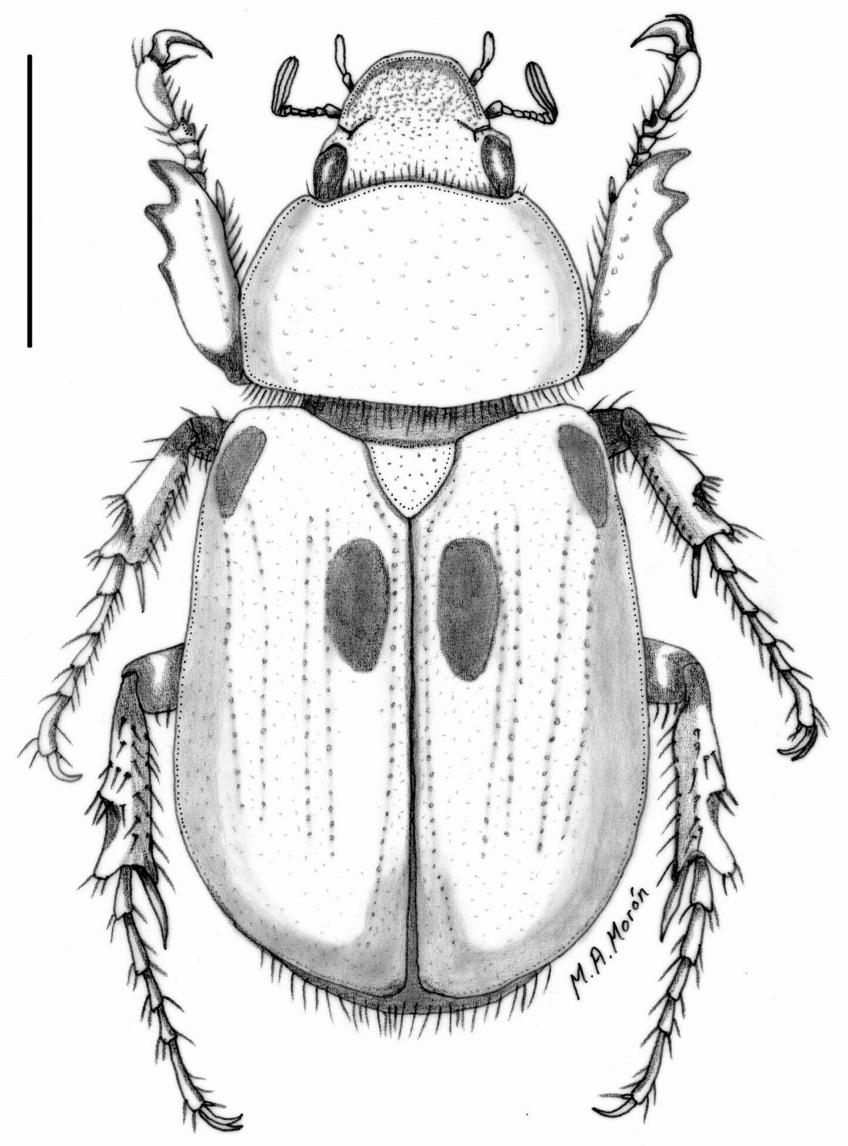

Figura 3. Aspecto dorsal de un macho de Ancognatha falsa (Arrow). Escala $10 \mathrm{~mm}$. 
DYNASTINAE, Oryctini.

Strategus Hope. Solo se registraron un macho y una hembra de $S$. aloeus en la localidad de Chignautla, atraídos por la trampa de luz durante mayo.

Xyloryctes Hope. Se capturaron 49 ejemplares (22 machos y 27 hembras) de X. furcatus atraídos por las luces de la trampa o el alumbrado en las localidades de km. 9 TeziutlánMartínez de la Torre, Chignautla, km.13 Teziutlán-Hueyapan y San Diego, durante mayo (1), junio (46), julio (1), agosto (1).

DYNASTINAE, Dynastini.

Dynastes Kirby. En San Diego se colectaron dos hembras y un macho de D. hyllus atraídos por la trampa de luz en julio y agosto.

RUTELINAE, Rutelini, Heterosternina

Parisolea Bates. Solo fue posible obtener un macho de P. pallida en la trampa de luz situada en el km. 13 Teziutlán-Hueyapan durante mayo.

RUTELINAE, Rutelini, Rutelina.

Plusiotis Burmeister. Se capturaron 10 ejemplares atraídos por las luces que representan a cuatro especies: un macho y cuatro hembras de $P$. sallei en Chignautla y San Diego durante junio (1), julio (2) y octubre (2); dos machos y una hembra de $P$. costata en San Diego y en Km. 9 Teziutlán-Martínez de la Torre en junio (2) y octubre (1); una hembra de P. aurofoveata en el km.13 Teziutlán-Hueyapan en el mes de abril; y una hembra de $P$. adelaida en Chignautla en el mes de febrero.

Chrysina Kirby. Al ser atraídos por las luces de la trampa y el alumbrado público del km. 9 Teziutlán-Martínez de la Torre, San Diego y km. 13 Teziutlán-Hueyapan, fueron capturados 108 ejemplares (53 hembras y 55 machos) de C. macropus en mayo (8), junio (40), julio (41), agosto (6) y septiembre (13). En San Diego también fue posible obtener una hembra y dos machos de $C$. peruviana en julio y septiembre.

\section{RUTELINAE, Anomalini}

Anomala Samouelle. En total se capturaron 39 ejemplares atraídos por las luces, que representan a seis especies: en el Km. 9 Teziutlán-Martínez de la Torre se registraron dos machos y una hembra de $A$. chevrolati en mayo (2) y junio (1) y siete machos y tres hembras de $A$. donovani en marzo (4) abril (3) y mayo (3); en San Juan Acateno se encontraron tres machos y cuatro hembras de $A$. denticollis en el mes de marzo, y dos machos y cuatro hembras de $A$. undulata en el mes de junio; y en el km 13 Teziutlán-Hueyapan se colectaron dos machos y dos hembras de $A$. undulata en el mes de mayo, dos machos de $A$. terroni en el mes de junio, y tres machos y dos hembras de $A$. stricticoptera en septiembre (3) y octubre (2).

Callistethus Blanchard. Con ayuda de la trampa de luz se colectaron 12 hembras de $C$. cupricollis en el km 9 Teziutlán-Martínez de la Torre durante junio (3), julio (6) y agosto (3); y en el km. 13 Teziutlán.-Hueyapan se localizó en el mes de junio un macho de $C$. vidua sobre un arbusto no identificado.

RUTELINAE, Anoplognathini, Platycoeliina

Platycoelia Burmeister. Únicamente se obtuvieron dos hembras de P. humeralis atraídas por la trampa de luz situada en el km 9 Teziutlán-Martínez de la Torre durante los meses de mayo y junio. 
SCARABAEIDAE, SCARABAEINAE, Scarabaeini

Deltochilum Escholtz. Se colectaron 6 hembras y 4 machos de D. mexicanum en necrotrampas en San Juan Acateno y km. 9 Teziutlán-Martínez de la Torre en los meses de julio (3), agosto (2), febrero (3) y abril (2).

\section{SCARABAEINAE, Coprini}

Copris Geoffroy. Bajo excrementos bovinos se colectaron 6 machos y 9 hembras de $C$. incertus en la localidad situada en el km 13 Teziutlán-Hueyapan durante marzo (6), junio (2) y julio (7).

Ontherus Erichson. Se encontraron 11 machos y 9 hembras de O. mexicanus (Fig. 4) atraídos por el alumbrado público y la trampa de luz mercurial durante febrero (1), junio (14), julio (3) y octubre (2) en las localidades ubicadas en el km 13 Teziutlán-Hueyapan, y en el km 9 Teziutlán-Martínez de la Torre y San Diego.

Dichotomius Hope. Durante junio y octubre se obtuvieron un macho y una hembra de $D$. satanas en San Juan Acateno y San Diego, uno atraído por el alumbrado público y otro bajo excremento bovino.

\section{SCARABAEINAE, Onthophagini}

Onthophagus Latreille. Por medio de las necrotrampas en el km 9 Teziutlán-Martinez de la Torre y en el km 13 Teziutlán-Hueyapan, se capturaron 7 machos y 4 hembras de O. cyanellus durante marzo (1), mayo (1), junio (8) y julio (1), mientras que en San Juan Acateno se colectaron 4 hembras y un macho de $O$. nasicornis en julio (2) y octubre (3).

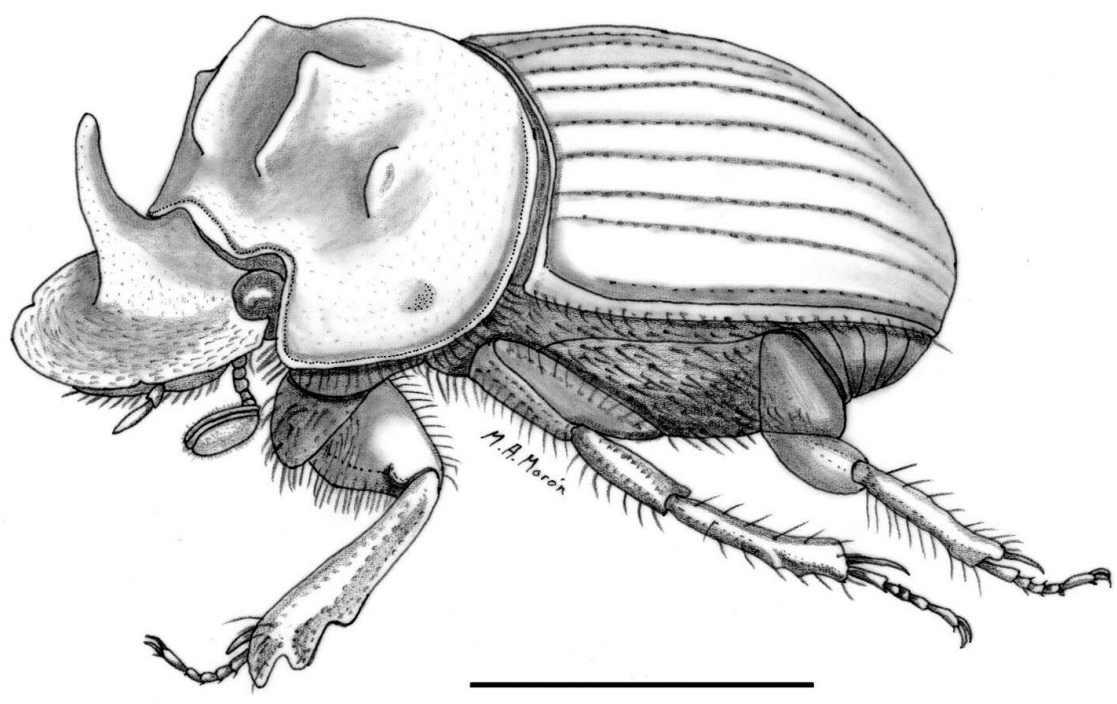

APHODIINAE, Aphodiini

Figura 4. Aspecto latero-dorsal de un macho de Ontherus mexicanus Harold. Escala $10 \mathrm{~mm}$. 
Labarrus Mulsant y Rey. Durante mayo se colectaron 56 ejemplares de L. pseudolividus, atraídos por la trampa de luz mercurial o extraídos del estiércol bovino en las localidad de km. 9 Teziutlán-Martínez de la Torre, y Chignautla.

$$
\text { APHODIINAE, Eupariini }
$$

Ataenius Harold. Durante junio se colectaron 24 ejemplares de una especie no identificada, atraídos por la trampa de luz en Chignautla.

$$
\text { PASSALIDAE, PASSALINAE, Passalini }
$$

Passalus Fabricius. En Chignautla se colectaron 5 hembras y 3 machos de P. punctatostriatus dentro de galerías excavadas en troncos descompuestos no identificados durante los meses de agosto (3) y septiembre (4), así como un ejemplar muy deteriorado que no fue posible identificar.

\section{PASSALINAE, Proculini}

Heliscus Zang. En las localidades de San Diego y en el km 9 Teziutlán-Martínez de la Torre fue posible colectar 4 hembras de H. tropicus, una de ellas atraída por el alumbrado público en mayo y las restantes dentro de troncos descompuestos en junio.

Odontotaenius Kuwert. En las cercanías de Chignautla en junio se encontró una pareja de $O$. zodiacus dentro de un tronco pequeño no identificado.

Proculejus Kaup. En la localidad del km 9 Teziutlán-Martínez de la Torre se capturaron 2 machos y 3 hembras de $P$. hirtus dentro de galerías excavadas en un tronco en descomposición no identificado.

Relaciones faunísticas y aspectos zoogeográficos. Dentro de los patrones propuestos por Halffter $(1976,1978)$ para la Zona de Transición Mexicana, se observa que cuatro géneros y siete especies quedan situados dentro del patrón de dispersión en el Altiplano Mexicano; cuatro géneros y seis especies siguen el patrón Mesoamericano de Montaña; ocho géneros y quince especies siguen el patrón Neotropical típico; cinco géneros y dieciocho especies pertenecen al patrón de dispersión Paleoamericano con amplio éxito (Cuadro 2).

A nivel genérico, la fauna de lamelicornios de Teziutlán muestra una similitud de $100 \%$ con las montañas de Hidalgo (Zacualtipán, Molango, Otongo, Tlanchinol), de $71.42 \%$ con Zacatlán, Puebla, de $58.62 \%$ con Cuetzalan, Puebla y de 55.17 \% con La Michilía, Durango. Debido a la condición montañosa de Teziutlán, con clima cálidosubhúmedo, los índices de similitud son menores con Los Tuxtlas, Veracruz (48.27\%), con Jojutla, Morelos (48\%), Tepic, Nayarit y Chamela, Jalisco $(41.37 \%)$ y la Sierra del Tentzo, Puebla (35\%).

En el nivel específico observamos que la fauna de Teziutlán está mayormente relacionada con las montañas de Hidalgo (80.70\%), Zacatlán (46.15\%) y Cuetzalan $(33.33 \%)$ en el estado de Puebla, y que sus menores índices de similitud corresponden con la sierra del Tentzo, Puebla (12.24\%), Los Tuxtlas, Veracruz (17.54\%), Jojutla, Morelos y Tepic, Nayarit (14.03\%), Chamela, Jalisco (7.01\%) y La Michilia, Durango (5.26\%). 
Cuadro 2. Patrones de Dispersión de los Lamellicornia de Teziutlán, en México.

\begin{tabular}{|c|c|c|c|}
\hline Altiplano Mexicano & Neotropical Típico & $\begin{array}{l}\text { Paleoamericano con } \\
\text { amplio éxito }\end{array}$ & $\begin{array}{c}\text { Mesoamericano } \\
\text { de montaña }\end{array}$ \\
\hline $\begin{array}{l}\text { Diplotaxis } \\
\text { Macrodactylus } \\
\text { Orizabus } \\
\text { Xyloryctes }\end{array}$ & $\begin{array}{l}\text { Strategus } \\
\text { Cyclocephala } \\
\text { Ligyrus } \\
\text { Dynastes } \\
\text { Dichotomius } \\
\text { Deltochilum } \\
\text { Ataenius } \\
\text { Passalus }\end{array}$ & $\begin{array}{l}\text { Copris } \\
\text { Phyllophaga } \\
\text { Anomala } \\
\text { Onthophagus } \\
\text { Aphodius }\end{array}$ & $\begin{array}{l}\text { Proculejus } \\
\text { Plusiotis } \\
\text { Chrysina } \\
\text { Ancognatha } \\
\text { Platycoelia } \\
\text { Parisolea }\end{array}$ \\
\hline
\end{tabular}

El análisis de los datos con el método de agrupamiento nos proporcionó tres árboles igualmente parsimoniosos, de los cuales elegimos el segundo árbol como el mas representativo, porque en el árbol de consenso estricto se colapsaron los nodos que relacionan las localidades de La Joya y Sierra del Tentzo, Puebla, con las localidades influenciadas por condiciones tropicales, debido a sus valores de bootstrap comparativamente menores (ver el apartado de Discusión).

\section{DISCUSIÓN}

Aspectos fenológicos, ecológicos y faunísticos. Los coleópteros Lamellicornios de Teziutlán se encuentran activos casi todo el año, pero alcanzan su mayor abundancia en los meses de marzo, mayo, junio, julio y octubre (Fig. 5). Por lo general esto se debe a que en esos meses se presentan las lluvias mas intensas, y por lo tanto, las condiciones mas adecuadas para la alimentación y la reproducción. Este patrón de presenta en otras localidades del país ya estudiadas por Morón (1981, 1994), Morón \& Deloya (1991), y Morón-Ríos \& Morón (2001). En cuanto al número de especies encontramos que los meses con mayor abundancia de especies son mayo y junio, con 18 especies, abril con 13 especies, octubre con 11 especies y febrero con 10 especies.

En los meses de noviembre, diciembre y enero no se realizaron colectas, ya que las principales vías de comunicación hacía los sitios de muestreo resultaron seriamente dañadas por las lluvias de octubre de 1999, por lo que era difícil llegar a los sitios establecidos. Además las bajas temperaturas que se presentaron al anochecer, ocasionaron que la actividad de la entomofauna disminuyera, hasta el punto en que durante dos días de noviembre no fue posible capturar ningún ejemplar.

La actividad de vuelo en las especies fotófilas de Teziutlán comenzó entre las 19:00-19:20 hrs y fue en aumento hasta alcanzar el mayor número de especies y ejemplares entre las 20:00-21:30 hrs. para disminuir al bajar la temperatura entre las 22:30- 23:00 hrs. 


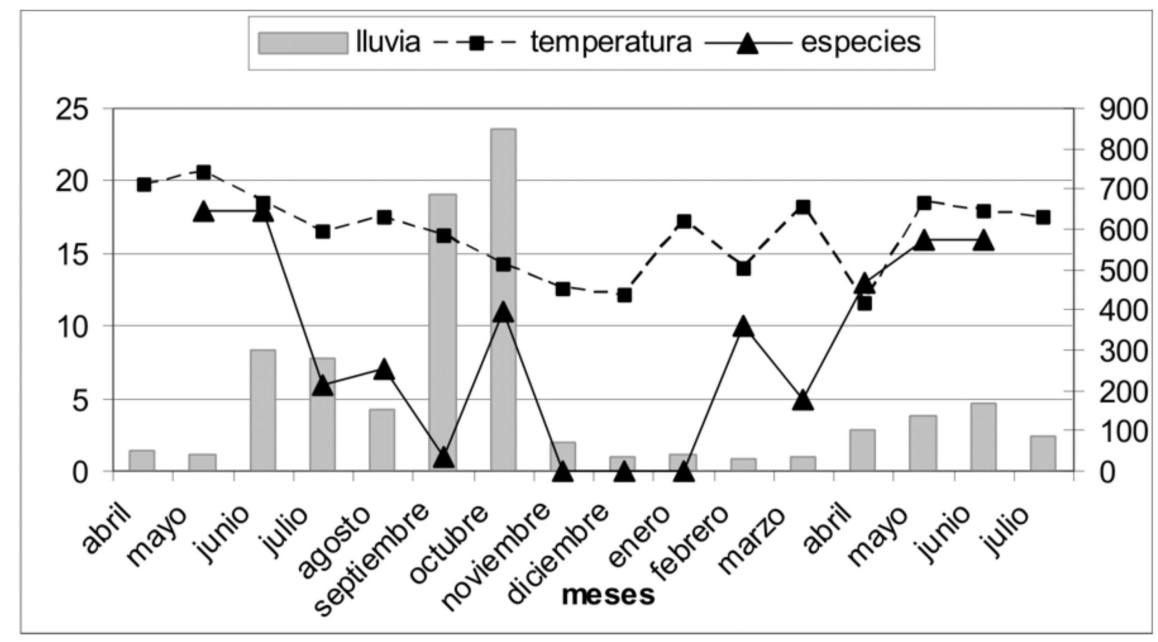

Figura 5. Distribución mensual del número de especies de Scarabaeoidea en relación con la temperatura y la precipitación en Teziutlán, Puebla.

De acuerdo con los gremios basados en los hábitos alimentarios propuestos por Morón y Deloya (1990), en el municipio de Teziutlán encontramos que los filorizófagos incluyen siete especies de Phyllophaga, cuatro especies de Cyclocephala, una especie de Ancognatha, seis especies de Anomala, dos especies de Isonychus y tres especies de Diplotaxis. Los filo-xilófagos están representados por cuatro especies de Plusiotis y dos especies de Chrysina. Entre los sapro-rizo-xilófagos se encontraron las especies de Ligyrus, Orizabus, Xyloryctes y Strategus. Los caulosaprófagos solo están representados por Dynastes hyllus. Los copro-necrófagos incluyen una especie de Copris, dos especies de Dichotomius, una especie de Deltochilum, una especie de Ontherus y dos especies de Onthophagus. Entre los sapro-endocópridos se encontraron dos especies de los géneros Ataenius y Aphodius. Los saproxilófagos están representados por una especie de Passalus y tres especies de los géneros Heliscus, Proculejus y Odontotaenius.

En la muestra total es notable el predominio de siete especies: Cyclocephala weidneri (391 ejemplares), Hoplia squamifera (368), Macrodactylus mexicanus (174), Phyllophaga vetula (151), P. xanthe (123), Cyclocephala jalapensis (113) y Chrysina macropus (108 ejemplares), las cuales representan el 68.5\% de los 2,082 ejemplares de coleópteros escarabaeoideos capturados en la región de Teziutlán.

$\mathrm{Al}$ analizar los datos con el método de agrupamiento para definir las relaciones existentes a nivel específico entre las faunas estudiadas (Fig. 6), observamos que en un primer conjunto se agrupan las localidades con predominio de especies asociadas 
con los climas templado-húmedo y húmedo-frío donde prosperan los bosques de pino-encino, allí las localidades de Zacatlán y Teziutlán se integran en un clado muy relacionado con Zacualtipán, formando un subgrupo oriental de montaña, en tanto que La Michilía y Villa de Allende se reúnen en el otro subgrupo centro-occidental de montaña.

Hacia la base del siguiente conjunto (Fig. 6) se ubican las localidades de El Triunfo, Chiapas, La Joya y El Tentzo, Puebla, en una posición de transición entre las comunidades de los bosques de pino-encino y las comunidades con mayor predominio tropical, representadas en los dos clados siguientes por el subconjunto correspondiente al bosque tropical caducifolio y subcaducifolio de la vertiente del Pacífico (Tepic, Chamela, Jojutla) y el subconjunto asociado con el bosque tropical perennifolio o subperennifolio de la vertiente del Golfo de México (Cuetzala, Otongo, Chajul y Los Tuxtlas), quedando Villa Las Rosas en una posición tropical transicional.

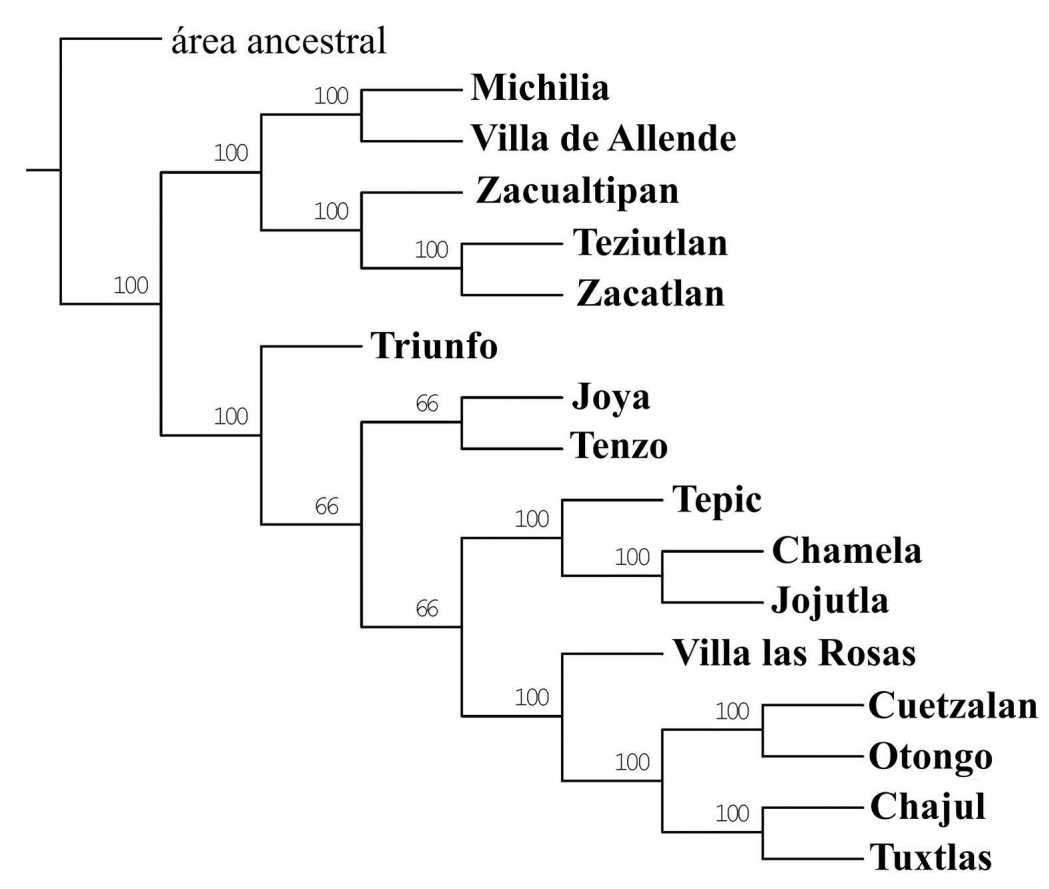

Figura 6. Relaciones a nivel específico entre las faunas de coleópteros Scarabaeoidea de 16 localidades mexicanas. Árbol 2 de 3, 100 búsquedas heurísticas (Longitud $=848$, Índice de consistencia $=89$, Índice de retención $=88$ ). Ver texto. 
La diversidad del municipio de Teziutlán es representativa de una región montañosa templada-húmeda y templado-frío, donde a pesar de la perturbación y otros factores que han alterado los ecosistemas de la zona, se obtuvieron cinco nuevos registros específicos para el estado de Puebla (Cuadro 3), lo que nos demuestra que el estado tiene una riqueza de lamelicornios considerable, similar a otros estados de la república que cuentan con estudios mucho mas extensos.

Cuadro 3. Nuevos registros de Scarabaeoidea para el estado de Puebla

\begin{tabular}{lll}
\hline \multicolumn{1}{c}{ Especies } & \multicolumn{1}{c}{ Registros anteriores } & \multicolumn{1}{c}{ Nuevos registros para Puebla } \\
\hline Plusiotis aurofoveata & Hidalgo, Veracruz & Km.13 Teziutlán-Hueyapan \\
Anomala terroni & Hidalgo & Km. 9 Teziutlán-Martinez de la \\
& & Torre \\
Platycoelia humeralis & Hidalgo, Ver, Oax, Chis. & Km.13 Teziutlán-Hueyapan \\
Phyllophaga angulicollis & Hidalgo, Oaxaca & Km.13 Teziutlán-Hueyapan \\
Phyllophaga godmani & Veracruz & Km 13 Teziutlán-Hueyapan \\
\hline
\end{tabular}

Teziutlán puede ser considerado (lo mismo que Zacatlán y Cuetzalan) como sitios de transición para las especies de lamelicornios debido a su posición intermedia entre la vertiente del Golfo y el Altiplano Central y a la variedad de microhábitats, proporcionados por las irregularidades topográficas. Por lo mismo, tienen un papel importante como parte de los corredores biológicos de la Sierra Madre Oriental y el Eje Neovolcánico.

Aspectos agropecuarios. Entre las especies con importancia agrícola en la región destaca Phyllophaga vetula, cuyas larvas son consideradas como un plaga potencial, principalmente para los cultivos de maíz. Los adultos de Macrodactylus mexicanus y M. nigripes pueden afectar las inflorescencias del maíz y árboles frutales, y las larvas de algunas especies de Cyclocephala y Anomala, pueden causar perdidas en los cultivos de maíz, fríjol y hortalizas (Morón 1983, 2001, Aragón \& Morón 1998).

Agradecimientos. A los Dres. Lino Zumaquero, Guadalupe Mayen y Jesús Francisco López Olguín (Benemérita Universidad Autónoma de Puebla-BUAP) y dos revisores anónimos, por las sugerencias que permitieron mejorar este trabajo. A la maestra Ana María Tapia Rojas (BUAP) por su colaboración en el trabajo de campo y durante la preparación del material colectado. Estos resultados representan una contribución al proyecto "Diversidad de los Coleópteros Scarabaeoidea del Estado de Puebla (II) apoyado por el Instituto de Ciencias, BUAP y la Comisión Nacional para el Conocimiento y Uso de la Biodiversidad (CONABIO) mediante el convenio FB626/R024/98 y a la línea de investigación "Coleópteros Lamelicornios de América Latina" apoyada con recursos de la cuenta 2000910011 del Instituto de Ecología, A.C. (Xalapa, Veracruz). 


\section{LITERATURA CITADA}

Alcázar-Ruiz, J.A., A. Morón-Ríos \& M. A. Morón, 2003. Fauna de Coleoptera Melolonthidae de Villa Las Rosas, Chiapas, México. Acta Zoológica Mexicana (n.s.) 88: 59-86

Aragón, A. \& M. A. Morón, 1998. Evaluación del daño ocasionado por el complejo "gallina ciega" (Coleoptera: Melolonthidae) en el estado de Puebla. Pp. 143-149. In: M. A. Morón y A. Aragón (eds.). Avances en el estudio de la diversidad, importancia y manejo de los coleópteros edaficolas americanos. Publicación especial Benemérita Universidad Autónoma de Puebla y Sociedad Mexicana de Entomología, Puebla, México.

Aragón, A., M.A. Morón, A. M. Tapia \& R. Rojas-García, 2001. Fauna de Coleoptera Melolonthidae en el rancho "La Joya", Atlixco, Puebla, México. Acta Zoológica Mexicana (n.s.) 83:143-164

Carrillo-Ruiz, H. \& M. A. Morón, 2003. Fauna de Coleoptera Scarabaeoidea de Cuetzalan del Progreso, Puebla, México. Acta Zoológica Mexicana (n.s.) 88: 87-121

Deloya, C. M. A. Morón \& J. M. Lobo, 1995. Coleoptera Lamellicornia (Macleay, 1819) del sur del estado de Morelos, México. Acta Zoológica Mexicana (n.s.) 65: 1-19

Halffter, G. 1976. Distribución de los insectos en la Zona de Transición Mexicana, relaciones en la entomofauna de Norteamérica. Folia Entomológica Mexicana 35: 1- 40

. 1978. Un nuevo patrón de dispersión en la Zona de Transición Mexicana: el Mesoamericano de Montaña. Folia Entomológica Mexicana 39-40: 219-222

Goloboff, P. 1999. NONA ver. 2. Published by the author. Tucumán, Argentina.

INEGI, 1993a. Teziutlán, Estado de Puebla. Cuaderno estadístico municipal. Secretaria de Gobernación del Estado de Puebla, H. Ayuntamiento de Teziutlán e Instituto Nacional de Estadística, Geografía e Informática. $25 \mathrm{pp}$.

. 1993b. Síntesis Geográfica del Estado de Puebla. Instituto Nacional de Estadística, Geografía e Informática. México.

Morón, M. A. 1979. Fauna de coleópteros Lamelicornios de la Estación de Biología Tropical UNAM "Los Tuxtlas, Ver. México. Anales del Instituto de Biología. UNAM, (ser. Zoología) 50(1): 375-454 1981. Fauna de coleópteros Melolonthidae de la Reserva de la Biosfera "La Michilía", Durango, México. Folia Entomológica Mexicana 50: 3-69

1983. Introducción a la biosistemática y ecología de los coleópteros Melolonthidae edafícolas en México. pp. 1-13. In: II Mesa Redonda sobre Plagas del Suelo. Sociedad Mexicana de Entomología, Colegio de Posgraduados y Depto. Parasitología, Universidad Autónoma de Chapingo, México.

. 1994. Fauna de Coleoptera Lamellicornia en las montañas del noroeste de Hidalgo, México. Acta Zoológica Mexicana (n.s.) 65: 7-29

1997. Inventarios faunísticos de los Coleoptera Melolonthidae Neotropicales con potencial como bioindicadores. Giornale Italiano di Entomologia 8: 265-274

2001. Larvas de escarabajos del suelo en México. Acta Zoológica Mexicana (n.s.) núm. Esp. 1: $111-130$

Morón, M. A., Aragón A., Tapia A. M. \& R. Rojas, 2000. Coleópteros Lamellicornios de la sierra del Tentzo, Puebla, México. Acta Zoológica Mexicana (n.s.) 79: 77-102.

Morón, M. A. \& C. Deloya, 1990. Los Coleoptera Lamellicornia de la Reserva de la Biosfera La Michilía, Durango, México. Folia Entomológica Mexicana 81: 209-283

Morón, M. A., C. Deloya \& L. Delgado, 1988. Fauna de Coleópteros Melolonthidae, Scarabaeidae y Trogidae de la región de Chamela, Jalisco, México. Folia Entomológica Mexicana 77: 313-378

Morón, M. A., C. Deloya, A. Ramírez-Campos \& S. Hernández-Rodríguez, 1998. Fauna de Coleoptera Lamellicornia de la región de Tepic, Nayarit, México. Acta Zoológica Mexicana (n.s.) 75: 73116 
Morón, M. A., B. C. Ratcliffe \& C. Deloya, 1997. Atlas de los Escarabajos de México. vol. 1. Sociedad Mexicana de Entomología y CONABIO, México.

Morón, M. A. \& R. Terrón, 1984. Distribución altitudinal y estacional de los insectos necrófilos de la Sierra Norte de Hidalgo, México. Acta Zoológica Mexicana (n.s.) 3: 1-47

Morón, M. A., F. J. Villalobos \& C. Deloya, 1985. Fauna de coleópteros Lamelicornios de Boca del Chajul, Chiapas, México. Folia Entomológica Mexicana 66: 57-118

Morón, M. A. \& S. Zaragoza, 1976. Coleópteros Melolonthidae y Scarabaeidae de Villa de Allende, México. Anales del Instiuto de Biología. UNAM, (ser. Zool.) 47(2): 83-118

Morón-Ríos, A. \& M. A. Morón, 2001. La fauna de Coleoptera Melolonthidae de la Reserva de la Biosfera "El Triunfo", Chiapas, México. Acta Zoológica Mexicana (n.s.) 84: 1-25

Nixon, K, C. 2002. WinClada ver 1.00.08. Published by the author. Ithaca, New York.

Reyes-Novelo, E. \& M. A. Morón, 2005. Fauna de Coleoptera Melolonthidae y Passalidae de Tzucacab y Conkal, Yucatán, México. Acta Zoológica Mexicana (n.s.) 21(2): 15-49

Recibido: 14 de septiembre de 2007

Aceptado: 10 de marzo de 2008 


\section{APÉNDICE I}

Lista de especies de Coleoptera lamellicornia de la región de Teziutlán, Puebla.

* Nuevos registros para el estado de Puebla.

\section{I.- MELOLONTHIDAE \\ 1.- Melolonthinae

$$
\text { A) Melolonthini }
$$

Phyllophaga (Phyllophaga) angulicollis (Bates, 1888)*

Phyllophaga (Phyllophaga) atra (Moser, 1918)

Phyllophaga (Phyllophaga) godmani (Bates, 1889)*

Phyllophaga (Phyllophaga) scissa (Bates, 1888)

Phyllophaga (Phyllophaga) vetula (Horn, 1887)

Phyllopaga (Phyllophaga) xanthe (Bates, 1888)

Phyllophaga (Phytalus) sp. aff. bucephala (Bates, 1888)

Phyllophaga (Chlaenobia) sp. aff. ciliatipes (Blanchard, 1850)

B) Diplotaxini

Diplotaxis consentanea Moser, 1955

Diplotaxis fossifrons Bates, 1918

Diplotaxis simplex Blanchard, 1850

$$
\text { C) Macrodactylini. }
$$

Macrodactylus mexicanus Burmeister, 1845

Macrodactylus nigripes Bates, 1887

Isonychus ocellatus Burmeister, 1855

Isonychus piperitus Bates, 1887

$$
\text { 2.- Hopliinae. }
$$

Hoplia squamifera Burmeister, 1844

Hoplia asperula Bates, 1887

3.- Rutelinae

Anomalini.

Anomala chevrolati Bates, 1888

Anomala denticollis Bates, 1888

Anomala donovani Stephens, 1830

Anomala sticticoptera Blanchard, 1850

Anomala terroni Morón y Nogueira, 1998*

Anomala undulata Melsheimer, 1844

Callistethus cupricollis (Chevrolat, 1834)

Callistethus vidua (Newman, 1838)

Anoplognathini

Platycoelia humeralis Bates, 1888*

Heterosternina

Parisolea pallida (Candeze, 1869)

Rutelini.

Chrysina macropus (Francillon, 1775)

Chrysina peruviana (Kirby, 1828)

Plusiotis adelaida (Hope, 1840)

Plusiotis aurofoveata Morón 1981*

Plusiotis costata Blanchard, 1850

Plusiotis sallei Boucard, 1845

\section{4.- Dynastinae}

Cyclocephalini

Ancognatha falsa (Arrow)

Cyclocephala fasciolata Bates, 1888

Cyclocephala jalapensis Casey, 1915

Cyclocephala lunulata Burmeister, 1847

Cyclocephala lurida coahuilae Bates, 1888

Cyclocephala melanocephala (Fabricius, 1775)

Cyclocephala sexpunctata Laporte de Castelnau, 1840

Cyclocephala weidneri Endrödi, 1964

Pentodontini

Ligyrus sallei Bates, 1888

Orizabus clunalis Leconte, 1856

Oryctini.

Strategus aloeus (Linné, 1758)

Xylorytes furcatus Burmeister, 1847

Dynastini.

Dynastes hyllus Chevrolat, 1843

\section{II.- SCARABAEIDAE}

1.- Scarabaeinae

Scarabaeini.

Deltochilum mexicanum Bates, 1848

Coprini.

Dichotomius satanas Harold, 1867

Copris incertus Say, 1835

Ontherus mexicanus Harold, 1868

Onthophagini.

Onthophagus cyanellus Bates, 1887

Onthophagus nasicornis Harold, 1869

2.- Aphodiinae

A) Aphodiini

Labarrus pseudolividus (Balthasar, 1950)

B) Eupariini

Ataenius sp.

III.- PASSALIDAE

1.- Passalinae

Passalini

Passalus punctatostriatus Percheron, 1867

Passalus sp.

Proculini

Odontotaenius zodiacus Truqui, 1857

Proculejus hirtus Truqui, 1857

Heliscus tropicus Percheron, 1835 


\section{APÉNDICE II}

Clave para identificar las especies de coleópteros lamelicornios de Teziutlán, Puebla, México.

Cuerpo robusto u ovalado. Maza antenal con las lamelas capaces de juntarse entre sí durante el reposo.

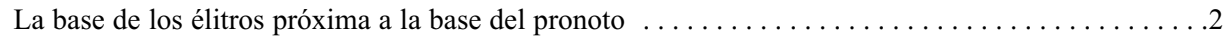
1' Cuerpo alargado y plano. Los artejos antenales capaces de curvarse, la maza antenal con las lamelas separadas entre sí. La base de los élitros separada del pronoto . . . . . . . . . . PASSALIDAE

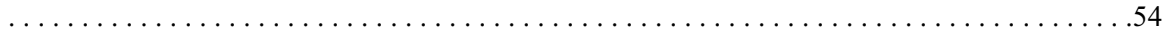
Maza antenal opaca con tres lamelas. Esternitos abdominales reducidos o fusionados en la región mesial. Estigmas respiratorios cubiertos por los élitros (condición laparosticti) SCARABAEIDAE

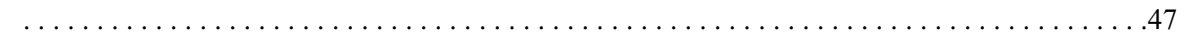

2' Maza antenal brillante, con sedas formadas por tres lamelas o mas. Esternitos abdominales no reducidos. Los dos últimos pares de estigmas respiratorios no cubiertos por los élitros. (condición

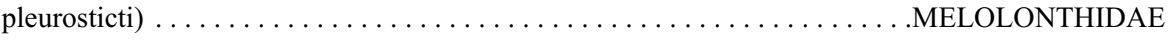

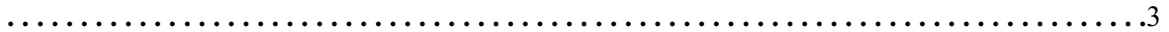

Cuerpo cubierto por sedas escamiformes. Metatibias con una corona de sedas espiniformes, sin espolón apical. Con una uña metatarsal. Longitud corporal menor a $7 \mathrm{~mm} \ldots \ldots \ldots \ldots \ldots$. . . . . . . . .

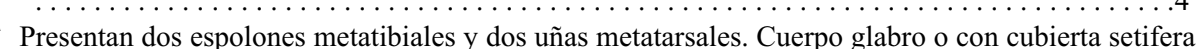

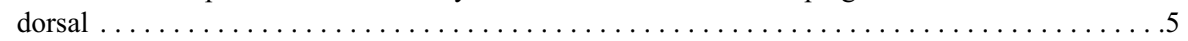

4. Antenas formadas por 10 artejos. Pronoto y élitros con manchas o franjas simétricas

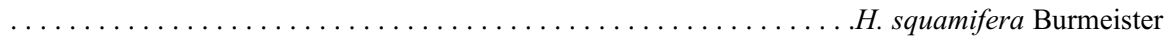

4' Antenas formadas por nueve artejos. Pronoto con manchas simétricas, élitros con franjas asimétricas

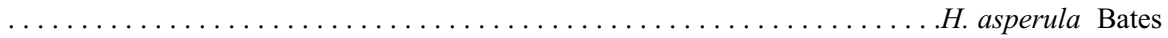

5. Uñas de los meso y metatarsos de igual longitud y grosor. Dimorfismo sexual variable . . . . . .6

5' Uñas meso y metatarsales de diferente longitud y grosor. Sin tubérculos o cuernos en la cabeza ...

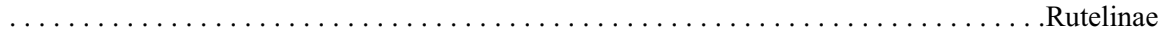

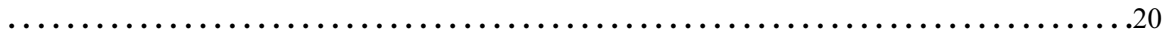

6. Borde anterior del labro visible. Mandíbulas cubiertas por el clípeo. Todas las uñas tarsales bífidas

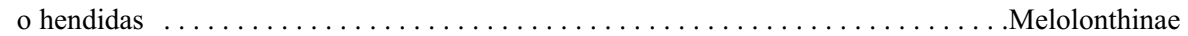

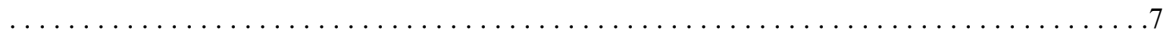

6' Borde anterior del labro oculto bajo el clípeo. Bordes anterior y lateral de las mandíbulas expuestos a los lados del clípeo. Uñas meso y metatarsales sencillas . . . . . . . . . . . . . . Dynastinae

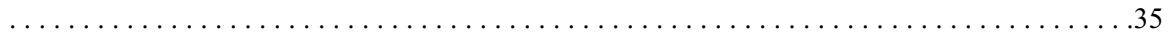

7. Procoxas trasversales poco sobresalientes $\ldots \ldots \ldots \ldots \ldots \ldots \ldots \ldots \ldots \ldots \ldots \ldots$ Melolonthini

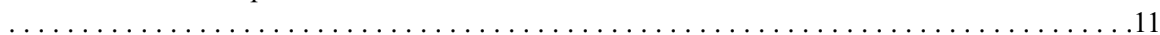

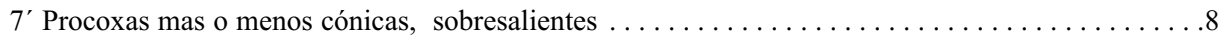

8. Cuerpo cubierto por sedas blancas o amarillentas. Placa pigidial alargada, delgada o semitriangular. Quinto esternito más largo que el cuarto $\ldots \ldots \ldots \ldots \ldots \ldots \ldots \ldots \ldots \ldots \ldots$ Macrodactylini

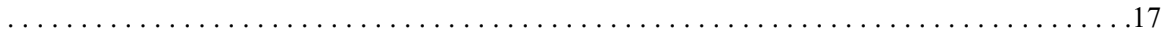

8' Cuerpo con escasas sedas. Placa pigidial pequeña. Quinto esternito abdominal de igual tamaño que

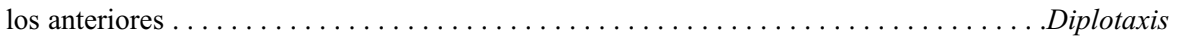

9. Antenas formadas por nueve artejos. Clípeo trapezoidal con el borde apical proyectado hacia arriba. Élitros con una serie de puntos profundos dispersos. Color pardo rojizo a naranja. Longitud corporal

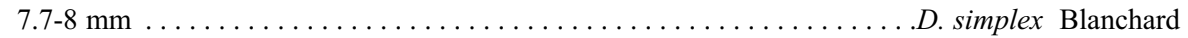

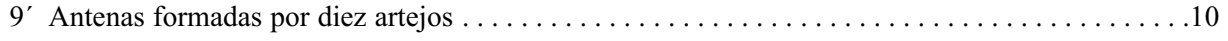


10. Clípeo sinuado, proyectado en forma de dentículos. Meso y metafémures robustos, con dos quillas a lo largo de la región lateral. Color pardo rojizo, oscuro o claro. Longitud corporal $8.3-9.3 \mathrm{~mm}$

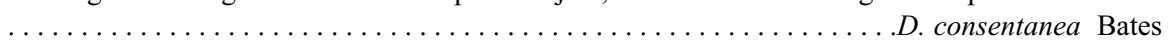

10' Clípeo bilobulado. Pronoto con la región mesial mas obscura, sin margen basal. Color pardo rojizo oscuro casi negro. Longitud corporal $11.5 \mathrm{~mm} \ldots \ldots \ldots \ldots \ldots$. fossifrons Moser

11. Maza antenal formada por nueve artejos, puede ser mas larga que los artejos procedentes $\ldots .12$

11' Maza antenal formada por diez artejos y es mas corta o de igual tamaño que el resto de los

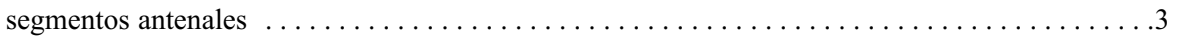

12. Protibias con dos dentículos apicales. Uñas hendidas. Región dorsal glabra. Cápsula genital con los parámeros divergentes, redondeados, edeago corto sin ornamentos. Cuerpo amarillento rojizo .P. (Chlaenobia) sp. aff. ciliatipes (Blanchard)

12' Pronoto negro con dos manchas laterales amarillentas. Élitros amarillentos con dos manchas pardo rojizas delgadas, desde la base de los élitros hasta la región posterior. Uñas protarsales hendidas. Borde inferior de las uñas metatarsales ligeramente aserrado. Longitud corporal $13 \mathrm{~mm}$ $\ldots \ldots \ldots \ldots \ldots \ldots \ldots \ldots \ldots \ldots \ldots \ldots \ldots \ldots \ldots \ldots \ldots \ldots$ (Phytalus) sp. aff. bucephala (Bates)

13. Dentículos intermedios de las uñas tan largos como el dentículo apical. Esternitos abdominales IIIV con dos pequeñas protuberancias en la región mesial. Cápsula genital con los parámeros cortos, redondeados, con dos espinas grandes y largas cercanas al ápice. Edeago en el ápice curvado ventralmente $\ldots \ldots \ldots \ldots \ldots \ldots \ldots \ldots \ldots \ldots \ldots \ldots \ldots \ldots \ldots \ldots$ (Phyllophaga) xanthe (Bates)

13' Dentículos intermedios mas cortos que el dentículo apical .......................

14. Placa anal masculina con un reborde basal bilobulado o sinuado. Esternito V con una zona granulosa mesial. Cápsula genital con los parámeros cortos, poco visibles, de diferente tamaño y en forma de dentículos. Edeago con un ornamento final delgado, y muy recurvado. Cuerpo cubierto por sedas grandes. Longitud corporal 16.2 a $18 \mathrm{~mm}$................ (Phyllophaga) vetula (Horn.)

14' Placa anal masculina sin reborde basal, bilobulada o sinuada. Cuerpo glabro o región dorsal con

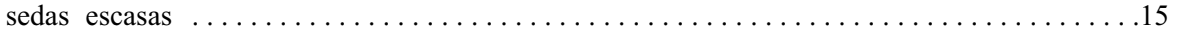

15. Cuerpo dorsalmente con escasas sedas. Placa pigidial semitriangular punteada, cápsula genital con los parámeros largos, rectos. Edeago ancho con ornamentos esclerosados delgados y alargados. Longitud corporal $17.2 \mathrm{~mm} \ldots \ldots \ldots \ldots \ldots \ldots \ldots$.(Phyllophaga) angulicollis (Bates)

15' Cobertura dorsal escasa o ausente. Con un reborde basal a lo ancho de la abertura anal . . ..16

16. Placa anal con dos pequeños tubérculos centrales. Cápsula genital con los parámeros largos, separados, curvos. Edeago hendido, con la región mesial dorsal sin ornamentos aparentes. Longitud corporal $19.1 \mathrm{~mm} \ldots \ldots \ldots \ldots \ldots \ldots \ldots \ldots \ldots \ldots \ldots \ldots \ldots \ldots \ldots \ldots$ (Phyllophaga) sccisa (Bates)

16' Placa anal sin tubérculos. Cápsula genital con los parámeros alargados sinuados, edeago con soporte tubular esclerosado. Longitud corporal $24.4 \mathrm{~mm} \ldots \ldots \ldots \ldots . .$. . (Phyllophaga) atra (Moser)

17. Élitros robustos hacia la parte posterior. Pronoto semitrapezopidal. Placa pigidial

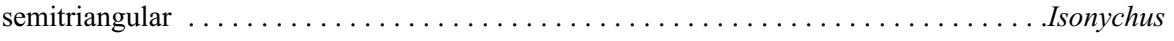

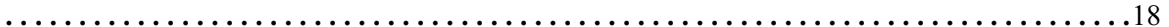

$17^{\prime}$ Élitros alargados. Pronoto de forma pentagonal. Placa pigidial alargada . . . . . Macrodactylus

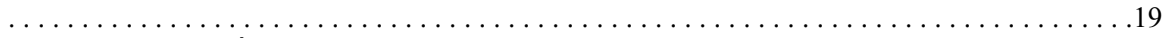

18. Clípeo bilobulado. Élitros con manchas oceladas obscuras, simétricas, dos de las cuales son más grandes que el resto. Parámeros con proyecciones angulosas. Longitud corporal 11-11.5 mm

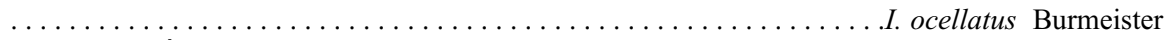

18' Clípeo recto. Élitros estriados y con puntos pequeños poco notables, cada uno con una seda fina y erecta. Parámeros sin proyecciones. Longitud corporal 12.7 a $14 \mathrm{~mm}$......... . piperitus Bates 
19. Clípeo sinuado. Cada élitro con siete estrías oceladas. Tibia y fémures de color anaranjado predominante. Parámeros con sedas en la porción distal de sus bordes exteriores. Longitud corporal

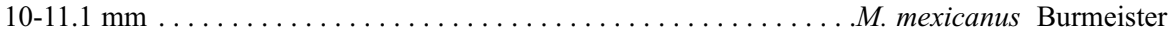

19' Clípeo recto. Cada élitro con una a dos estrías oceladas poco aparentes. Tibias, fémures y tarsos negros. Longitud corporal $10-11 \mathrm{~mm} \ldots \ldots \ldots \ldots \ldots \ldots \ldots \ldots \ldots \ldots \ldots \ldots$ nigripes Bates

Labro colocado en posición horizontal o paralela con respecto al clípeo, normalmente separado de éste

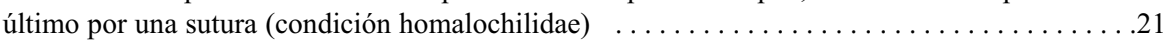

$20^{\prime}$ Labro colocado en posición vertical con respecto al clípeo y poco fusionado con éste (condición orthochilidae). Región dorsal del cuerpo muy convexa. Región ventral casi plana. Color verde

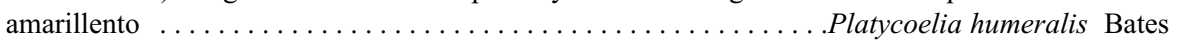

21. Con diez artejos antenales. Élitros sin borde membranoso. Placa pigidial semitriangular. Protibias con tres dentículos apicales $\ldots \ldots \ldots \ldots \ldots \ldots \ldots \ldots \ldots \ldots \ldots$. . . . . . . . . . . . . . . . . . . . . . .

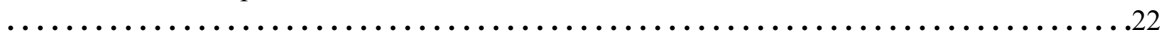

21' Con nueve artejos antenales. Élitros con borde membranoso. Placa pigidial generalmente ovalada. Protibias con dos dentículos apicales $\ldots \ldots \ldots \ldots \ldots \ldots \ldots \ldots \ldots \ldots \ldots \ldots \ldots \ldots \ldots \ldots$. . . . . . . . . . . . . . .

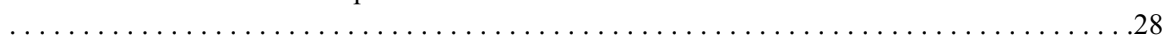

22. Presentan sutura fronto clipeal completa (Heterosternina). Mandíbulas con tres dentículos apicales. Clípeo estrecho y sinuado. Coloración general amarillenta o blanquecina. Longitud corporal

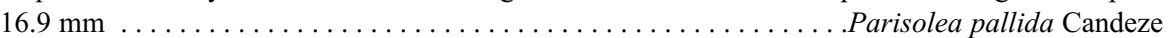

$22^{\prime}$ Presentan sutura fronto clipeal incompleta. Pronoto con un margen basal incompleto o interrumpido

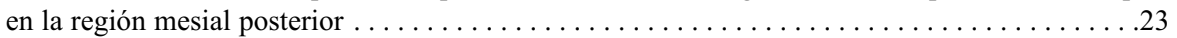

23. Clípeo semitrapezoidal, angulado. Élitros sin estrías aparentes. Dimorfismo sexual acentuado.

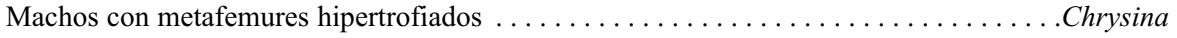

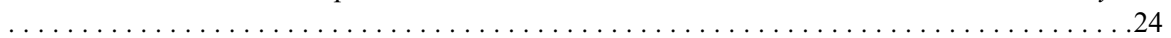

23’ Clípeo redondeado. Élitros con estrías bien marcadas. Dimorfismo sexual escaso. Machos no

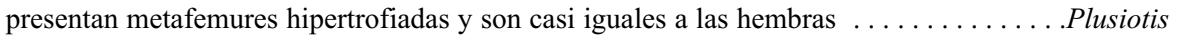

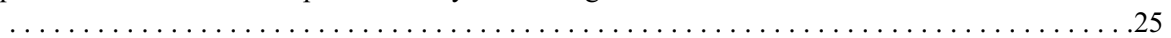

24. Metaesternón prominente en los machos, con escasas sedas finas. Machos con una proyección apical posterior en las metacoxas. Regiones ventrales verde claro con reflejos cobrizos o dorados iridiscentes. Longitud corporal 31-40 mm ................ Chrysina macropus (Francillon)

$24^{\prime}$ Metaesternón poco prominente en los dos sexos, con abundantes sedas blanquecinas. Machos sin proyección apical posterior en las metacoxas. Regiones ventrales verde azulado obscuro con reflejos plateados intensos iridiscentes. Longitud corporal 34-35 mm ...... Chrysina peruviana (Kirby)

25. Frente con una depresión regional mesial. Clípeo abultado. Pronoto con dos manchas pardo rojizas laterales y una central en forma de " $T$ ". Élitros con franjas intercaladas pardo rojizas, verdes y

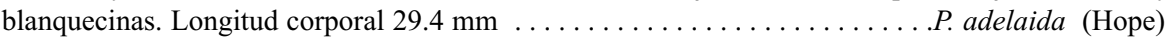

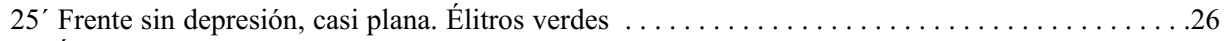

26. Élitros con puntos toscos e irregulares y fosetas irregulares doradas o amarillentas. Protarsos rosadoverdosos. Parámeros ensanchados angulosos, simétricos, con el ápice brevemente escotado. Longitud corporal $33.3 \mathrm{~mm} \ldots \ldots \ldots \ldots \ldots \ldots \ldots \ldots \ldots \ldots$ aurofoveata Morón

26' Élitros con estrías bien definidas por puntuación continua. Clípeo con puntuación rugosa

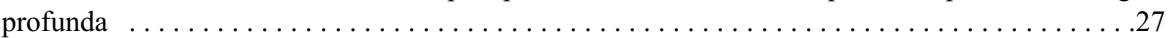

27. Labro sinuado. Tarsos rojizos a violeta metálico. Clípeo punteado rugoso. Parámeros angulosos, simétricos. Longitud corporal 14.7-30.5 mm ................... sallei Boucard

27' Labro hendido. Tarsos verde claro iridiscente, con reflejos cobrizos. Parámeros hendidos, simétricos, con un dentículo apical. Longitud corporal 30.7-31 mm

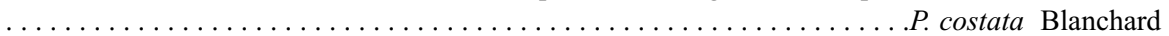


28. Con proyección mesoesternal larga o corta $\ldots \ldots \ldots \ldots \ldots \ldots \ldots \ldots \ldots \ldots \ldots \ldots$ Callistethus

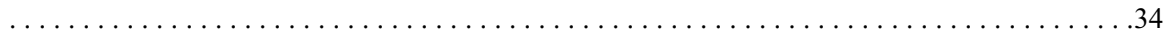

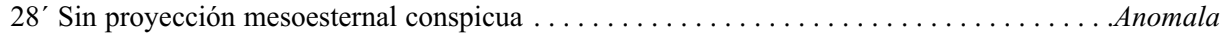

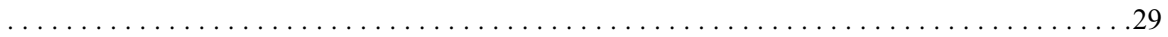

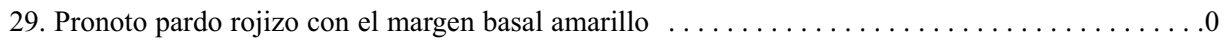

29' Maza antenal de igual longitud o más larga que el resto de los artejos. Élitros con manchas

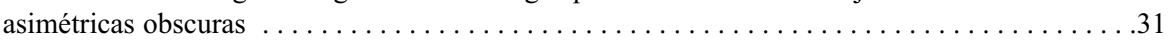

Élitros amarillentos, estriados, con puntuación notable. Margen basal del pronoto amarillento con una línea mesial oscura. Placa pigidial amarillenta. Cápsula genital con los parámeros separados. Longitud corporal $14-15 \mathrm{~mm} \ldots \ldots \ldots \ldots \ldots \ldots \ldots \ldots \ldots \ldots \ldots \ldots \ldots$ chevrolati Bates

$30^{\prime}$ Élitros con dos manchas negras en los calla apicales, dos manchas centrales y dos debajo de los calla humerales. Vestidura ventral larga, amarillenta. Longitud corporal $12-13 \mathrm{~mm}$

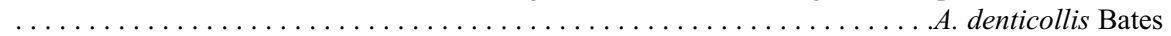

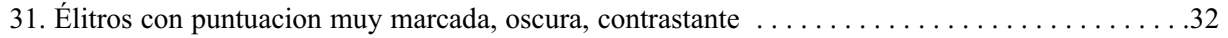

31' Élitros con puntuación fina y manchas transversales oscuras $\ldots \ldots \ldots \ldots \ldots \ldots \ldots \ldots \ldots$

32. Élitros amarillentos con puntuación asimétrica profunda pardo rojiza. Placa pigidial pardo rojiza con puntuación rugosa. Meso y metafémures con una quilla transversal completa. Longitud corporal 14-

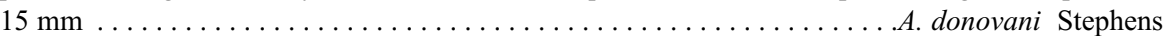

32' Élitros claros u obscuros con puntuación tosca, irregular, negra, sin cobertura dorsal. Ápice metatibial no ensanchado. Longitud corporal 14-17 mm ...........A. sticticoptera Blanchard

33. Frente con una ligera depresión mesial. Pronoto amarillento con una mancha central amplia obscura. Élitros con dos líneas de manchas transversales negras simétricas, quillas definidas por líneas de puntos profundos. Longitud corporal $10-11 \mathrm{~mm} . . . \ldots \ldots \ldots \ldots \ldots$. undulata Melsheimer

33' Frente con una amplia depresión semitriangular. Clípeo con dos manchas negras en la parte posterior. Pronoto con numerosas sedas cortas erectas y depresiones laterales amplias. Élitros con dos manchas humerales y apicales, así como una línea de manchas difusas. Longitud corporal

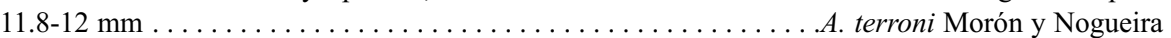

34. Machos con coloración amarilla rojiza en el clípeo y márgenes laterales del pronoto. Abdomen, fémures, tibias, maza antenal, centro del pronoto, élitros y tarsos negros brillantes. Hembras amarillo rojizo brillante. Ambos con élitros estriados. Proyección mesoesternal muy prominente. Machos con uñas protarsales interiores engrosadas finamente hendidas. Longitud corporal 10-12

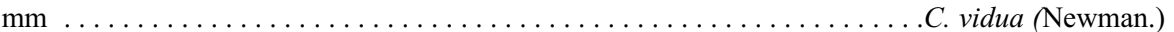

34' Cabeza y pronoto pardo rojizo con reflejos metálicos en ocasiones verdosos. Proyección mesoesternal corta, redondeada y con sedas; élitros con interestrías definidas por puntos pardo rojizos. ................................. C. cupricollis (Chevrolat)

35. Tarsos mas largos que las tibias. Dimorfismo sexual acentuado, machos con una proyección cefálica dirigida hacia el frente con el ápice agudo ligeramente hendido, con sedas amarillentas. Machos y hembras con élitros verde olivo o verde grisáceo, con manchas obscuras irregulares. Hembras con la cabeza y el pronoto negros. Longitud corporal $56-64.1 \mathrm{~mm}$. ...... Dynastes hyllus Chevrolat

35' Tarsos de igual tamaño o mas cortos que el resto de las tibias. Dimorfismo sexual variable . . . 37

36. Cabeza y pronoto sin carinas o tubérculos. Metatibias con los ápices poco ensanchados .......

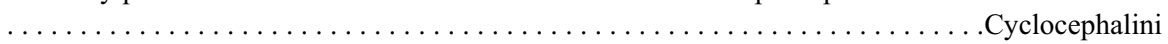

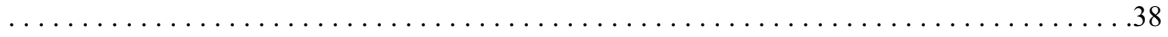

36' Cabeza o pronoto con carinas, depresiones o proyecciones ceratiformes. Metatibias con los ápices

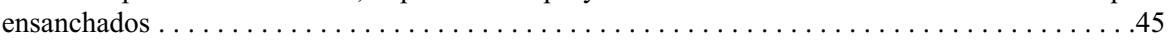


37. Clípeo un poco mas largo que ancho. Sutura fronto-clipeal incompleta. Pronoto con dos manchas pequeñas laterales. Élitros con cuatro manchas oscuras, dos pequeñas en los calla humerales y dos grandes en la región media (Fig. 3). Longitud corporal: 19-25 mm

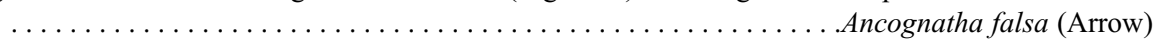

37’ Clípeo mas ancho que largo. Élitros con manchas negras simétricas . . . . . . . . Cyclocephala

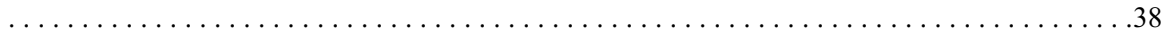

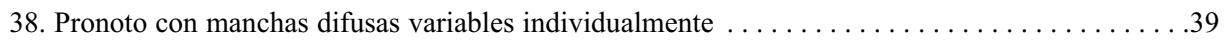

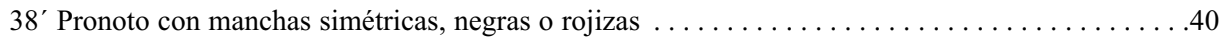

39. Clípeo convexo, ápice levantado. Élitros con manchas simétricas difusas. Placa pigidial glabra con puntuación rugosa. Longitud corporal $13.7-18.4 \mathrm{~mm} \ldots \ldots \ldots \ldots \ldots$. . . . . . . . . . Eneri Endrödi

39' Clípeo poco sinuado, pardo rojizo. Élitros con cuatro o más manchas simétricas. Prepigidio y placa anal cubiertos por sedas mas o menos largas. Longitud corporal 14.4-17.3 mm

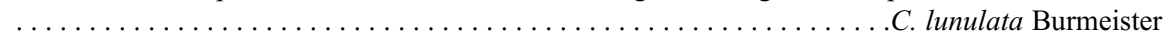

40. Coloración general negra. Élitros opacos con dos manchas rojizas o anaranjadas simétricas. Placa pigidial con puntuación y vestidura larga. Machos con protibias bidentadas. Hembras con protibias tridentadas. Longitud corporal $19-22 \mathrm{~mm}$. . . . . . . . . . . . . . . . . fasciolata Bates

$40^{\prime}$ Coloración dorsal pajiza, amarillenta o rojiza. Élitros con manchas negras simétricas o sin manchas

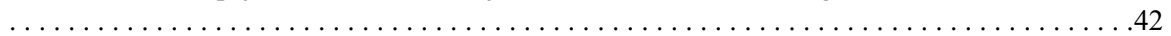

41. Pronoto pardo rojizo. Clípeo trapezoidal. Élitros amarillentos sin manchas oscuras, punteados densamente. Placa pigidial con puntuación rugosa. Longitud corporal 11.3-12 mm

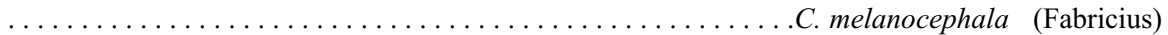

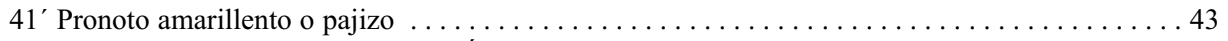

42. Pronoto con manchas poco claras. Élitros sin manchas, con reborde lateral. Placa pigidial triangular cubierta por sedas. Machos con la maza antenal más larga que el resto de los artejos procedentes. Longitud corporal $12-14.2 \mathrm{~mm} \ldots \ldots \ldots \ldots \ldots \ldots \ldots \ldots \ldots \ldots \ldots \ldots \ldots$ lurida coahuilae Bates

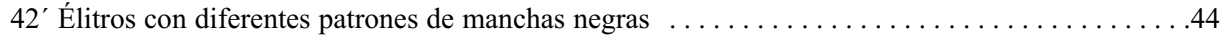

43. Cabeza, región ventral y patas negras. Pronoto con dos manchas laterales. Élitros con manchas simétricas que varían de forma individual. Parte posterior de los élitros con sedas largas. Placa pigidial cubierta por sedas largas y con puntuación rugosa. Longitud corporal 16.8-19 mm

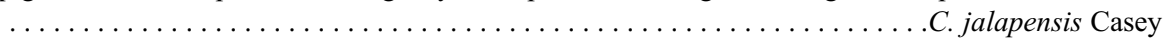

43' Pronoto con cuatro manchas negras, dos grandes en la región mesial y dos laterales pequeñas. Élitros con dos patrones melánicos simétricos, el primero con ocho manchas negras de diferente tamaño y el segundo con los élitros totalmente negros con dos franjas anaranjadas longitudinales. Longitud corporal $20-21.7 \mathrm{~mm} \ldots \ldots \ldots \ldots \ldots \ldots \ldots \ldots \ldots \ldots \ldots \ldots \ldots$. sexpunctata Castelnau

44. Metatibias con proyecciones apicales. Dimorfismo sexual acentuado. Clípeo estrecho ... Oryctini

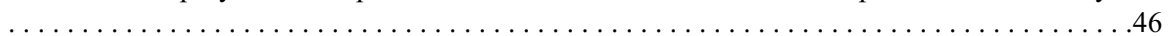

44' Metatibias sin proyecciones apicales. Clípeo ancho. Dimorfismo sexual escaso . . . . Pentodontini

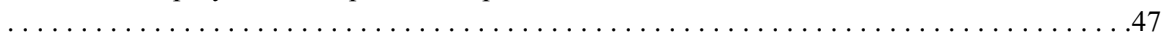

45. Clípeo bilobulado. Mandíbulas sin dentículos externos. Machos con una proyección ceratiforme en la frente. Hembras con un tubérculo frontal. Pronoto de los machos con un proyección central hendida o bifurcada, bajo la cual se encuentra una cavidad amplia con puntuación rugosa. Longitud corporal $26-35.8 \mathrm{~mm} . \ldots \ldots \ldots \ldots \ldots \ldots \ldots \ldots \ldots \ldots \ldots \ldots$ Xyctes furcatus Burmeister

45' Clípeo triangular. Frente con dos tubérculos en los dos sexos. Machos con tres tubérculos y dos fosetas amplias en el pronoto. Hembras con una foseta amplia en el pronoto. Longitud corporal 29-

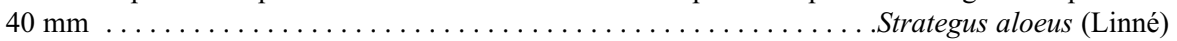


46. Ápice del clípeo ligeramente bidentado. Frente con dos tubérculos. Pronoto convexo. Protibias con tres dentículos grandes y dos mas pequeños intercalados. Machos con los tarsos engrosados.

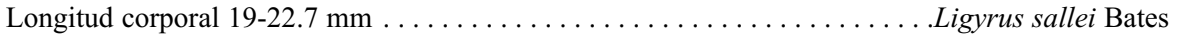

46 Ápice del clípeo redondeado, con una quilla postapical transversal. Frente con un tubérculo cónico. Pronoto con una proyección pequeña y una cavidad central cercanas al borde anterior. Hembras con protibias tridentadas. Machos sin dentículos en las protibias. Longitud corporal 24-27 mm Orizabus clunalis (LeConte)

47. Placa pigidial completamente, o en su mayor parte, oculta por los ápices de los élitros. Metatibias

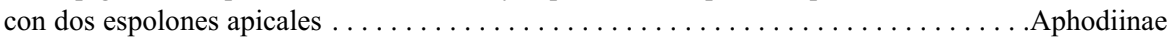

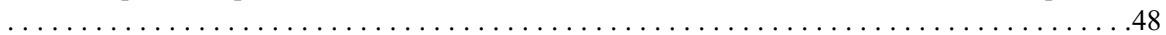

47' Placa pigidial totalmente expuesta. Metatibias con un espolón apical . . . . . . . Scarabaeinae

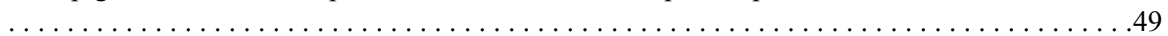

48. Meso y metatibias con dos carinas oblicuas en sus caras exteriores. Ápice de las metatibias con una corona de sedas rígidas. Regiones dorsales amarillentas, con manchas obscuras difusas. Longitud

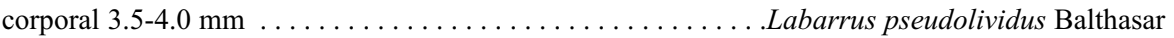

$48^{\prime}$ Meso y metatibias sin carinas en sus caras exteriores. Regiones dorsales pardo obscuras o rojizas.

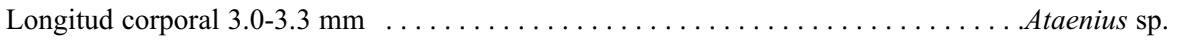

49. Meso y metatibias cortas, con sus ápices muy ensanchados. Cabeza y pronoto con proyecciones

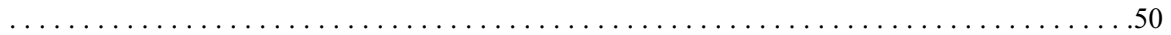

49' Meso y metatibias largas, delgadas y curvas, con sus ápices poco ensanchados. Clípeo con dos dentículos apicales. Élitros con cinco tubérculos pequeños en cada callus apical. Cuerpo azul obscuro con reflejos verdosos. Longitud corporal 19-26 mm

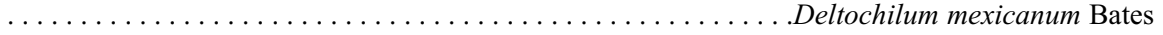

50. Tercer artejo de los palpos labiales bien desarrollado $\ldots \ldots \ldots \ldots \ldots \ldots \ldots \ldots \ldots \ldots \ldots$

$50^{\prime}$ Tercer artejo de los palpos labiales inconspicuo, reducido o ausente . . . . . . . Onthophagini

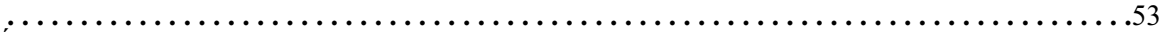

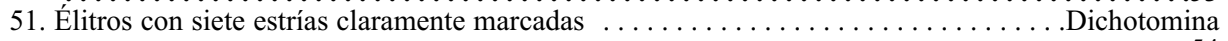

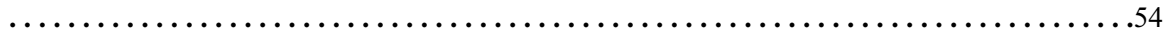

51' Élitros con ocho estrías. Clípeo hendido. Machos con un tubérculo clipeal delgado, largo y curvo, con un diente pequeño situado en la parte posterior de su base. Pronoto de los machos con dos proyecciones laterales laminares laterales y un tubérculo bifurcado central. Hembras con un tubérculo frontal, y sólo con una quilla transversal en el pronoto. Longitud corporal 16.2-18 mm

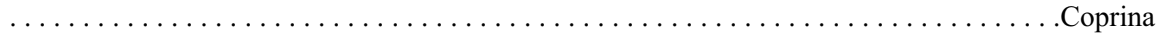

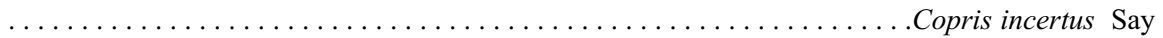

52. Abdomen de tamaño regular con sus segmentos alargados. Machos con una proyección laminar con el centro del clípeo y tres proyecciones transversales en el pronoto. Hembras con un tubérculo

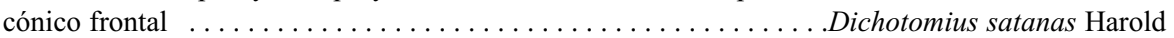

52' Abdomen muy corto con los segmentos reducidos. Machos con un tubérculo alargado en el centro del clípeo. Pronoto del macho con cuatro tubérculos centrales, con una cavidad central y dos cavidades laterales. Hembras con dos pequeños tubérculos frontales y el pronoto casi convexo. Longitud corporal $12.4-13 \mathrm{~mm} . \ldots \ldots \ldots \ldots \ldots \ldots \ldots \ldots$. . . . . . . . . merus mexicanus Harold

53. Borde del clípeo casi recto. Regiones dorsales opacas, negras o ligeramente azuladas. Pronoto de los machos muy convexo, con una tumescencia amplia. Pronoto de las hembras casi convexo. Longitud corporal $9-11.3 \mathrm{~mm} \ldots \ldots \ldots \ldots \ldots \ldots \ldots \ldots$ Onthophagus cyanellus Bates

53' Borde del clípeo con una laminilla semitriangular erecta en los machos, o claramente hendido en las hembras. Regiones dorsales brillantes, negras. Pronoto de los machos muy convexo, menos convexo en las hembras. Longitud corporal 7.3-7.7 mm . Onthophagus nasicornis Harold 
54. Clipeo expuesto, visible dorsalmente, con los ángulos anteriores desarrollados, sutura frontal

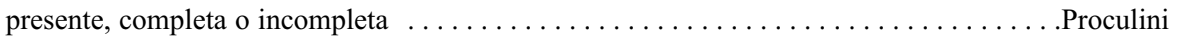

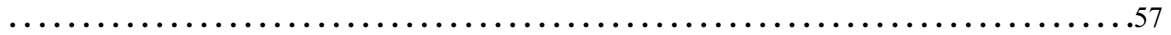

54' Clípeo oculto debajo de la frente, ángulos anteriores pequeños, debajo de los tubérculos externos.

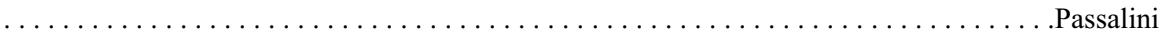

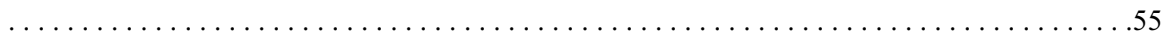

55. Estructura media frontal con una quilla transversal gruesa provista de un pequeño tubérculo central dirigido hacia el frente, en la cual se desarrollan dos quillas terminadas en tubérculos, élitros con sedas abundantes largas amarillentas en sus partes laterales. Longitud corporal $25-33 \mathrm{~mm}$

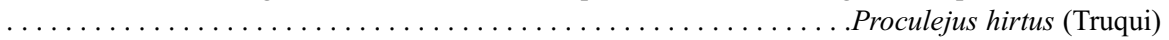

$55^{\prime}$ Estructura media frontal de otro tipo. Lados laterales de los élitros sin sedas abundantes

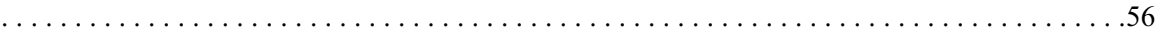

56. Estructura frontal con una quilla transversal gruesa, con una proyección central dirigida hacia delante, y dos quillas finas divergentes terminadas en tubérculos pequeños. Longitud corporal 20 -

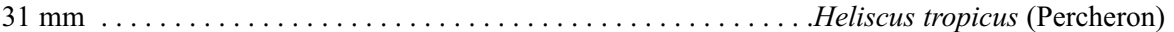

56' Estructura media frontal con una proyección ceratiforme gruesa, región anterior de la frente redondeada. Diente interno de las mandíbulas sin tubérculo pequeño basal, borde anterior del clípeo muy ligeramente bisinuado. Longitud corporal 30-38 mm ..... Odontotaenius zodiacus (Truqui)

57. Borde anterior de la frente recto o ligeramente escotado en el centro. Labro toscamente punteado, con sedas. Clípeo con tubérculos laterales prominentes. Longitud corporal 22-29 mm

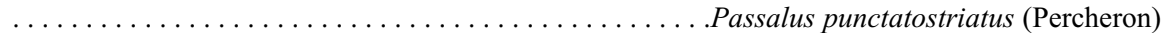

57' Borde anterior de la frente recurvado. Labro finamente punteado, sin sedas. Clípeo con tubérculos laterales poco marcados. Longitud corporal $24 \mathrm{~mm} \ldots \ldots \ldots \ldots \ldots \ldots$.................... 